IZA DP No. 10133

The Effect of Gender-Targeted Conditional Cash Transfers on Household Expenditures: Evidence from a Randomized Experiment

Alex Armand

Orazio Attanasio

Pedro Carneiro

Valérie Lechene

August 2016 


\title{
The Effect of Gender-Targeted Conditional Cash Transfers on Household Expenditures: Evidence from a Randomized Experiment
}

\author{
Alex Armand \\ University of Navarra, NCID \\ Orazio Attanasio \\ University College London \\ Pedro Carneiro \\ University College London, IFS, CeMMAP and IZA \\ Valérie Lechene \\ University College London
}

Discussion Paper No. 10133

August 2016

\author{
IZA \\ P.O. Box 7240 \\ 53072 Bonn \\ Germany \\ Phone: +49-228-3894-0 \\ Fax: +49-228-3894-180 \\ E-mail: iza@iza.org
}

Any opinions expressed here are those of the author(s) and not those of IZA. Research published in this series may include views on policy, but the institute itself takes no institutional policy positions. The IZA research network is committed to the IZA Guiding Principles of Research Integrity.

The Institute for the Study of Labor (IZA) in Bonn is a local and virtual international research center and a place of communication between science, politics and business. IZA is an independent nonprofit organization supported by Deutsche Post Foundation. The center is associated with the University of Bonn and offers a stimulating research environment through its international network, workshops and conferences, data service, project support, research visits and doctoral program. IZA engages in (i) original and internationally competitive research in all fields of labor economics, (ii) development of policy concepts, and (iii) dissemination of research results and concepts to the interested public.

IZA Discussion Papers often represent preliminary work and are circulated to encourage discussion. Citation of such a paper should account for its provisional character. A revised version may be available directly from the author. 


\section{ABSTRACT \\ The Effect of Gender-Targeted Conditional Cash Transfers on Household Expenditures: Evidence from a Randomized Experiment ${ }^{*}$}

This paper studies the differential effect of targeting cash transfers to men or women on the structure of household expenditures on non-durables. We study a policy intervention in the Republic of Macedonia, offering cash transfers to poor households, conditional on having their children attending secondary school. The recipient of the transfer is randomized across municipalities to be either the household head or the mother. Using data collected to evaluate the conditional cash transfer program, we show that the gender of the recipient has an effect on the structure of expenditure shares. Targeting transfers to women increases the expenditure share on food by about 4 to $5 \%$. To study the allocation of expenditures within the food basket, we estimate a demand system for food and we find that targeting payments to mothers induces, for different food categories, not only a significant intercept shift, but also a change in the slope of the Engel curve.

JEL Classification: D12, D13, E21, O12

Keywords: $\quad$ CCT, intra-household, gender, expenditure

Corresponding author:

Pedro Carneiro

Department of Economics

University College London

Gower Street

London WC1E 6BT

United Kingdom

E-mail: p.carneiro@ucl.ac.uk

\footnotetext{
* We gratefully acknowledge the financial support from 3ie International Initiative for Impact Evaluation (grant reference OW4-1022). Carneiro acknowledges the support of the Economic and Social Research Council (ESRC) through a grant (RES-589-28-0001) to the Centre for Microdata Methods and Practice.
} 


\section{Introduction}

When designing cash transfer programs it is important to understand whether fathers and mothers spend income differently (in particular, transfer income). Until now, it has been difficult to test this question directly, due to lack of suitable data. Even in the case of the Conditional Cash Transfer (CCT) program Progresa/Oportunidades, where non-durables exogenous cash transfers were given to a randomly selected group of mothers, it is only possible to compare the spending patterns of recipient households with those of non recipient households with the same levels of income. In that context, it has been shown that income that is exogenously given to mothers is spent differently from income generated by the labour supply choices of household members. This finding suggests that mothers and fathers probably spend income differently, but does not establish this as an experimental fact, nor does it measure the magnitude of the difference, without imposing some structure on the data.

Nevertheless, most CCT programs implemented in developing countries explicitly target women within households by choosing them as the recipient of the transfer. The aim of this practice is to improve women's well-being, and to increase their participation in household decision making. The notion that control over resources leads to control over decision making is supported by a large body of research using observational data, showing that the amount of resources that each household member contributes to the family affects the allocation of household expenditures (see for instance Thomas 1990; Schultz 1990; Bourguignon et al. 1993; Browning et al. 1994; Phipps and Burton 1998). However, relative earned/unearned incomes might depend on decisions that are correlated with observed outcomes, making it difficult to distinguish whether different allocations of expenditures are due to relative incomes, or due to other household-level unobservable characteristics.

Focusing on food, different studies find that following an increase in total expenditure induced by a CCT transfer, households tend to allocate a larger share of total expenditures to food. This contradicts the usual assumption that food is a necessity, and therefore, that its share should decrease following an increase in total consumption. One possible explanation for this pattern is that the increase in food budget shares results from a change in control over household resources, which is induced by the transfer.

Attanasio and Lechene (2010) describe the effect of large cash transfers to women in the context of a CCT program (Progresa). They document that the food budget share does not decrease in rural Mexico, whilst total consumption increases as a consequence of the program, even though the transfer represents about 20 percent of income for the average household. At the same time, they show that food is a necessity, with a strong negative effect of income on the food budget share. Therefore, in the case of Progresa/Oportunidades, as income and total consumption are increased substantially by the program, the standard force pushing down the food budget share is counterbalanced by an effect of the program on the control of household resources, pushing up the food share, such that the net effect is nil. This finding is consistent with other studies focusing 
on Progresa in urban Mexico (Angelucci and Attanasio, 2009, 2013), on Familias en Acción in Colombia (Attanasio et al., 2012), and on Bono Solidario in Ecuador (Schady and Rosero, 2008).

In this paper, we use data from a CCT program implemented in Macedonia from 2010, which provides cash transfers to poor households, conditional on having their children enrolled in secondary school. This program has the unique feature of being a nationwide program in which the gender of the recipient was randomized across municipalities. In half of the municipalities the transfer is targeted to mothers, while in the other half it is targeted to the household head, who is the father of the child in the vast majority of households. While most other studies support that the gender of the transfer recipient affects the allocation of household expenditures, their findings constitute only indirect evidence that men and women spend income differently. This is the first time that the possibility of gathering direct evidence on the issue is made available. Benhassine et al. (2015) studied a similar transfer program in Morocco, featuring a degree of randomization of the gender of the recipient of the transfer. However, they report that the randomization on this dimension essentially failed in practice and that husbands appropriated the transfer. Furthermore, they find little or no effect of the transfer on outcomes. Akresh et al. (2012) study alternative cash transfer delivery mechanisms (among those the payment to mothers versus fathers) on household demand for preventative health services in rural Burkina Faso, but they do not study the effect on the allocation of household expenditures.

The design of the CCT program and the richness of the expenditure data allow us to examine whether expenditure patterns on non-durable goods differ depending upon the gender of the recipient of the transfer. We also estimate Engel curves for the budget shares of non-durables and for food categories within the food basket, and study whether they change with the gender of the transfer recipient. Throughout our analysis, we discuss and address issues related to the endogeneity of expenditure, schooling and program take-up.

We find that targeting CCT transfers to mothers has a positive effect on the food share of 4 to 5\%. This confirms that the puzzling finding in literature that CCT transfers increase both expenditure and the share allocated to food might indeed be due to an increase in the amount of resources controlled by the woman in the household. While this corresponds to just an intercept change in the food Engel curve, we find that, within the food basket, targeting transfers to women generates a more complex changes. We show that, for a variety of food categories, there is not only a change in the intercepts of Engel curves, but also in their slopes.

The remainder of the paper is organized as follows. In Section 2 we describe the study area and the design of the intervention, while in Section 3 we introduce our dataset. We discuss our empirical strategy in Section 4 and we present the results in Section 5. Section 6 concludes.

\section{The Macedonian CCT program}

The Macedonian Conditional Cash Transfer (CCT) for Secondary School Education is a social protection program aiming to increase secondary school enrolment and completion rates among 
children in the poorest households of the population. It was first implemented by the Macedonian Ministry of Labour and Social Policy (MLSP) in the Fall of 2010, and provided transfers to households conditional upon school-age children attending secondary school at least $85 \%$ of the time. The program was offered to beneficiaries of Social Financial Assistance (SFA), which is the largest income support program in Macedonia, accounting for around $0.5 \%$ of GDP, and $50 \%$ of total spending on social assistance (Verme, 2008). SFA is a mean-tested monetary transfer granted to people who are fit for work, who are socially not provided for, and who cannot support themselves. It is considered as the benefit of last resort, which means that it is provided if, after other benefits are taken-up, household income is still below a given threshold. ${ }^{1}$ The beneficiaries of SFA are mainly households in the lowest tail of the income distribution. In 2009, the World Bank reports that $55 \%$ of all SFA households are in the poorest income quintile, $22 \%$ are in the second-poorest quintile, and $11 \%$ are in the middle income quintile (The World Bank, 2009).

The total annual amount of the subsidy provided by the CCT if all conditions are met is 12000 MKD (roughly 240 USD), to be paid in quarterly instalments. The quarterly instalments correspond to the quarters that constitute a school year. CCT payments are made immediately after the school quarter is completed, and student attendance is checked. ${ }^{2}$ During the first two years of the program, the payment was processed via nominal cheques, which could be cashed in banks or post offices. Compliance with local guidelines governing the gender of the recipient is therefore easy to ensure, given that the full CCT management is computerized, and the payments are processed depending on the family composition originally entered in the social protection system.

The gender of the recipients of the transfer was randomized, allowing payments to be received by either the mother of the child or the household head. ${ }^{3}$ The household head is the recipient of the SFA transfer, and is generally a male. Among SFA recipients, the household head is the male partner in $90 \%$ of non single-parent households, which represent $88 \%$ of SFA households. Randomization of the payment modality was done at the municipality level, after stratifying municipalities by population size. The 84 municipalities composing the Republic of Macedonia were first divided into 7 groups depending on population size, and then randomized into two groups, one of which has 42 municipalities and where the transfer is paid to the mother of the child, and the other which also has 42 municipalities and where the transfer is paid to the household head, regardless of gender.

\footnotetext{
${ }^{1}$ Income support from this program is a minimum guaranteed income. The SFA benefit is equivalent to the difference between household income and the social assistance amount determined for the household, which depends on household size and time spent in SFA. The amount varies from 1825 MKD (around 40 USD) monthly for one-member household to 4500 MKD (around 98 USD) monthly for households with 5 or more members.

${ }^{2}$ The school year is divided in the following periods: September-October, November-December, January-March and April-June. Payments are scheduled for December, February, May and July. The attendance data is entered in the CCT system by each school's officers at the end of the reference period and payments are processed by the MLSP.

${ }^{3}$ The CCT program defines "Household Head" the person in the household that is registered at the Social Welfare Centre (SWC) for SFA. According its rulebook, the Household Head is, in priority order, the employed person in the household, the pensioner or the unemployed person representing the household.
} 


\section{Data}

Our data comes from two waves of the Macedonian Household Survey collected by the MLSP to evaluate the effect of the CCT program. The surveys include detailed information on a variety of household characteristics and outcomes (demographic characteristics, expenditures on durable and non durable goods, housing), and individual level information on household members (education, health, labour supply, time use).

\subsection{Sample structure and descriptive statistics}

The baseline survey took place between November and December 2010, coinciding with the beginning of the first school year in which the CCT program became available. ${ }^{4}$ At baseline, the population of eligible households was taken from the MLSP's electronic database of recipients of all types of financial assistance, which was assembled during the Summer of 2010 for the implementation of the program. This database was checked against hard-copy archives at the Social Welfare Centres (SWC), which administer social welfare provision at the local level. We identified 12481 SFA households with at least one child of secondary school age (15-18 years old), who therefore should be eligible for the CCT, and drew a random sample from this group. Our population of interest consists of households eligible for the CCT program during the summer before the introduction of the program, although some of these households were eventually found to be ineligible by the SWC (due, for example, to fraudulent under-reporting of income), while others never applied for the CCT even though they were eligible. The follow-up survey was collected during the Fall of 2012, after two years of program implementation.

In terms of family structure, our sample is quite diverse. Households can be composed of a single-parent or two-parents, and can be led by a woman or a man. Table 1 decomposes the full sample in categories depending on family type (single male parent, single female parent, or couples) and the residence of the household (whether living in a municipality in which transfers are paid to mothers, Mother municipalities, or in a municipality in which the transfers are paid to heads of households, HH municipalities). Since our objective is to focus on couples, we select only households in which both parents are present (sub-samples A1, A2, B1 and B2). In addition, to limit the household decision making to nuclear families, we exclude households where additional adult members, such as grandparents, are part of the family and living in the same dwelling, and we select only households with at least one child potentially eligible for the CCT (aged 14-18 years old). Including households with additional adult members introduces further heterogeneity in the household decision process, which we want to avoid here. We note, however, that our results are unchanged by the inclusion of these households in the analysis.

We obtain a sample of 1053 households at baseline, 94 of which were not interviewed at

\footnotetext{
${ }^{4}$ At baseline, households were interviewed during the first two months of the program, rather than before the start of the intervention. It is reasonable to believe that this timeline had no effect on baseline results, since the program implementation was very slow at the beginning and the first payments were processed only in March-April 2010. In contrast, the survey was completed by the end of December 2010.
} 
Table 1: Actual recipient of the transfer by type of household and municipality

\begin{tabular}{|c|c|c|c|c|c|}
\hline \multirow[b]{2}{*}{ Applicant } & \multirow[b]{2}{*}{$\begin{array}{l}\text { Presence of } \\
\text { partners }\end{array}$} & \multirow[b]{2}{*}{$\begin{array}{l}\text { Identity of the } \\
\text { Household head }\end{array}$} & \multicolumn{2}{|c|}{ Actual recipient if living in a... } & \multirow[b]{2}{*}{ Sub-sample } \\
\hline & & & HH Municipality & $\begin{array}{c}\text { MOTHER } \\
\text { Municipality }\end{array}$ & \\
\hline \multirow{4}{*}{ Yes } & \multirow{2}{*}{ Both Present } & Father & Father & Mother & $\overline{\mathbf{A 1}}$ \\
\hline & & Mother & Mother & Mother & $\mathbf{A 2}$ \\
\hline & Father only & Father & Father & Father & A3 \\
\hline & Mother only & Mother & Mother & Mother & A4 \\
\hline \multirow{4}{*}{ No } & \multirow{2}{*}{ Both Present } & Father & - & - & B1 \\
\hline & & Mother & - & - & $\mathbf{B 2}$ \\
\hline & Father only & Father & - & - & B3 \\
\hline & Mother only & Mother & - & - & B4 \\
\hline
\end{tabular}

Note. HH (Mother) municipalities are municipalities where the transfers are paid to heads of households (mothers). The actual recipient differs due to the decision to participate in the program and due to heterogeneity in the household structure. "--" indicates that no one in the household is receiving the transfer since the household does not participate in the program. The sub-sample selected for the analysis is reported in bold.

follow-up, giving us an attrition rate of $8.9 \%$. Attrition is not driven by the treatment modality. ${ }^{5}$ The follow-up sample includes only 830 households, where the additional reduction over and beyond attrition is due to the exclusion from the sample of households whose children do not meet the age criteria for participating in the programme any more. ${ }^{6}$

Table 2 presents means and standard deviations for household characteristics at baseline. Column 1 refers to the whole sample, while columns 2-3 refer respectively to households living in HH municipalities and in Mother municipalities. Households are composed on average by 4.5 members, and the household head is a man in $83 \%$ of the cases. The education of the household head is low: $50 \%$ completed upper primary education ( 8 years of schooling), and $20 \%$ completed only lower primary (4 years of schooling), or have no formal education at all. In terms of location of dwellings, $48 \%$ of households live in rural areas, and 14 percent live in Skopje, the capital city. When looking at the ethnic composition of our sample, the majority of households are of Macedonian (41\%) and Albanian (33\%) ethnicities. The residual 26\% is composed by Roma, Turk and other residual ethnic groups. Men tend to be more educated compared to women, with an average of 8 versus 7 years of schooling, respectively. At the same time, on average, husbands (with an average age of 45 in the sample) tend to be 3 years older than their wives.

Column 4 of Table 2 presents mean differences for all these variables between households living in HH municipalities and households living in Mother municipalities. At baseline, the two groups are balanced on all demographic characteristics reported in the table, with no mean difference statistically different than zero. Table 2 also shows a joint test checking the balance of all

\footnotetext{
${ }^{5}$ A probit regression on the probability of not being interviewed at follow-up on the Mother municipality dummy and on demographic controls returns a slightly higher probability for households living in mother municipalities. Results using inverse probability weighting (Wooldridge, 2010) to correct for attrition are consistent with our main results. See Appendix B.2 for a detailed discussion.

${ }^{6}$ The number of baseline households we can use in the follow-up analysis is much smaller than 1053-94=959, where 1053 is the sample size at baseline, and 94 are the attriters. The reason is that 299 baseline household become ineligible for the program at follow-up because their children have become too old to be eligible. The follow-up sample was however refreshed with a sample of 170 eligible households who were enrolled in the program during the second year of the program, giving us a final follow-up sample size of 1053-94-299+170=830. Appropriate re-weighting is carried out since, at follow-up, we over-sampled households participating in the program. The results are robust to the exclusion of these households (see Appendix B.2).
} 
these variables simultaneously. We run a probit regression of treatment assignment to a Mother municipality on household characteristics, and we test whether the coefficients in the regressions are jointly equal to zero. We do not reject the null hypothesis, which provides additional evidence that the households in the two groups were balanced at baseline. In summary, pre-program randomization was effective in achieving balance in the characteristics of sampled households.

\subsection{Expenditure shares and prices}

In what follows, we analyse expenditure shares and relate them to prices and other household level variables. Here we describe how expenditure shares and prices are constructed in our context.

\subsubsection{Total expenditure and budget shares}

Expenditure shares are built using available information about purchases and self-production on a variety of items consumed by the household. We aggregate our analysis on the main goods consumed by the household, such as food, alcohol and tobacco, clothing, schooling, health, utilities and other goods. Table 3 presents the description of each category considered in the analysis. ${ }^{7}$

Expenditure data is collected using a recall method. A detailed expenditure section was added to the household questionnaire and divided into sub-sections depending on the characteristics of the goods and their proposed frequency of purchase. The adopted frequencies are based upon the frequencies reported by the Macedonian Household Budget Survey, which is an annual survey collected by the Macedonian State Statistical Office, with the purpose of identifying expenditure patterns in the average Macedonian household. Based on these frequencies of purchase, the survey collected information about expenditures with a reference period of one week for food; one month for expenses related to health, personal hygiene, transportation costs, sport, culture and entertainment and for meals provided at school; six months for clothing, utensils for the house, toys for children, house and vehicle maintenance; and one year for utilities and for school-related costs.

Using information about expenditure on individual items, we computed an expenditure aggregate for non-durable goods. ${ }^{8}$ We first transform all the expenditures on non-durable goods to a comparable time period, and then we add up the expenditures on individual items (Deaton and Zaidi, 2002). For food items, we take into account not only what the household spent on purchases, but also what the household actually consumed from self-production. In order to impute the value of self-produced items, we use a set of prices built upon a proximity criteria. The first choice is to use prices directly from the household survey, for the cases in which the household purchased the same item. However for a large number of households, goods are either purchased or self-produced, and not both. In the latter case, prices at household level might not always be

\footnotetext{
${ }^{7}$ For food items, table B7 presents derivatives of food budget shares for each items contained in the sub-categories with respect to total food expenditure.

${ }^{8}$ Throughout the paper, we use total expenditure and food expenditure in real terms. We exploit geographical price variation using a Stone Price Index, as discussed in Section 3.2.2, and we subtract the index from nominal expenditure. Since prices are only available for food, the real adjustment can only be carried out using a Food Price Index.
} 
Table 2: Descriptive statistics on household characteristics at baseline, by treatment status

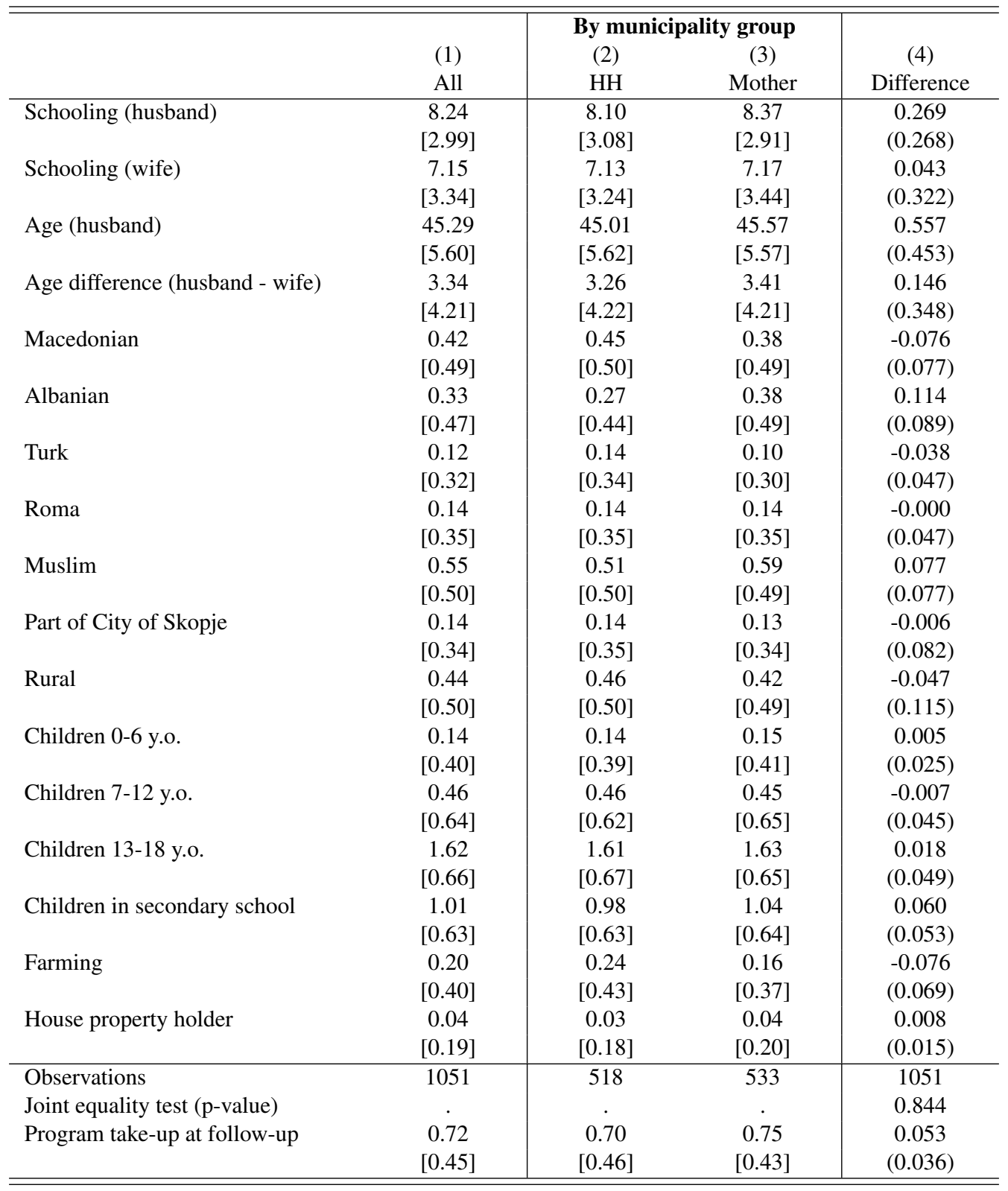

Note: $* * * \mathrm{p}<0.01, * * \mathrm{p}<0.05, * \mathrm{p}<0.1$. Columns $1-3$ report sample means for the whole sample and restricted to different treatment modalities, standard deviations in brackets. Column 4 reports the difference between (3) and (2) estimated using OLS regression of the correspondent variable on the treatment indicator and clustering standard errors (reported in parenthesis) at municipality level. To control for joint significance, we run a probit regression of the treatment indicator on the selected variables and we report p-values of an F-test for the joint significance of the coefficients. Treatment indicator is equal to 1 if the household lives in a Mother municipality and zero otherwise. Program take-up refers to the share of households enrolled in the CCT during either of the first two years of the program. 
Table 3: Description of goods and food items

\begin{tabular}{|c|c|}
\hline CATEGORY & DESCRIPTION \\
\hline Food & $\begin{array}{l}\text { Cereals, vegetables and fruit, meat, fish and dairy, coffee, tea and other beverages, } \\
\text { fats, salt and sugars and other food items. }\end{array}$ \\
\hline Alcohol and Tobacco & Beer, wine, other spirits, cigarettes and tobacco. \\
\hline Clothing & Clothing and footwear. \\
\hline Education & $\begin{array}{l}\text { Tuition fees, uniforms, school supplies, textbooks, additional courses, transportation } \\
\text { to school, meals at school and other school related expenses. }\end{array}$ \\
\hline Health & $\begin{array}{l}\text { Consultations, hospital services, medicines, surgical appliances, hearing aids, } \\
\text { glasses, x-rays, echocardiograms and laboratory tests, transportation cost to health } \\
\text { centers and other medical expenses. }\end{array}$ \\
\hline Utilities and other expenses & Electricity, gas, phone and mobile phone bills and other non-durable expenditures. \\
\hline FOOD CATEGORY & DESCRIPTION \\
\hline Starches & Bread, wheat flour, rice, pasta and other cereal products, potatoes and beans. \\
\hline Fruit and vegetables & Fresh vegetables and fruit, canned and pickled vegetables, nuts and dried fruit. \\
\hline Meat, fish and dairy & $\begin{array}{l}\text { Fresh, dried and smoked meat, fresh and canned fish, eggs, milk, yoghurt, cheese, } \\
\text { butter and other lipids. }\end{array}$ \\
\hline $\begin{array}{l}\text { Salt and sugars } \\
\text { Other food }\end{array}$ & Salties, sugar, honey, jam, chocolate, sweets and cookies, soft drinks, coffee and tea. \\
\hline Other food & All other food items. \\
\hline
\end{tabular}

Note. The definition of categories is based on the structure of the annual Household Budget Survey collected by the Macedonian State Statistical Office. Food items within food categories are defined on the basis of frequency of purchase and of familiarity with the item.

available. In order to overcome this problem, we compute median prices using observations on other households who have purchased the item, and living in the same or a nearby location. This procedure is discussed in detail in Section 3.2.2.

Table 4 presents descriptive statistics for expenditure and expenditure shares. Columns 1-2 present means and standard deviations, while columns 3-4 report instead mean differences across treatment groups at baseline. On average, food is the main component in the budget, accounting for 55\% of household expenditure. The Macedonian State Statistical Office reports that the mean share of food for a representative sample of households in 2012 is around 34\%. Our results are in line with the fact that we are focusing on the poorest sector of the Macedonian population.

In addition, households allocate $4 \%$ of the total budget to education, $13 \%$ to health and $19 \%$ to utilities and other expenses. Expenditure on tobacco and alcohol correspond to 3\% of household expenditure. Differences in expenditure shares across the two treatment modality groups are not statistically different from zero at baseline, providing additional evidence of baseline balance.

Within the food basket, several groups of (aggregated) food categories were identified, reflecting the structure of purchases of a typical Macedonian family. Table 3 presents the classification adopted in the paper, and describes the items in each category. Columns 1-2 in table 5 present the shares of food expenditure allocated to each of these food categories. The food with the highest share are starches, capturing on average $43 \%$ of total food expenditure. The next highest item is meat, fish and dairy, accounting for $35 \%$ of total food expenditure. 


\subsubsection{Unit values and Prices}

Since prices for every item are not available disaggregated at municipality or regional level, we approximate prices with unit values. However, we can compute unit values only for food items since information about quantities purchased and expenditures were collected only for food items, for which we also have information collected in shops. Data on shop prices at municipality or regional level for non-food items are not available either. To control for variation in prices for items other than food, in all specifications we proxy spatial variation using regional dummies, a control for whether the household lives in the capital city, and a dummy for rural municipalities. For food and its components, we use information on expenditures and quantities purchased for different items to build household-level prices (if the item is purchased) and municipality/regional-level unit prices.

We construct Stone price indexes at the level of the municipality for each food category, using information about unit values and expenditure shares. The weight of each median unit value is given by the sum of all individual household expenditures in a certain municipality on a certain item, divided by total expenditure in the municipality in the food category that the item belongs to. When computing median prices, we face the issue of capturing the local variation in prices when, for a few goods, there is no data on purchases in certain locations. To solve this problem, we use increasingly larger clusters, until we can find a reliable set of prices which we can then use to impute prices for the lower level clusters. In particular, median prices were computed starting from the lowest level of geographical clustering (municipality), and substituting for median prices at higher levels (region, and then country) in the case of missing purchases (see also Attanasio et al. 2013). We set the minimum acceptable number of observations per municipality per item at 6. Only when we observe a smaller number at the municipality level do we move to larger geographical clusters.

Median prices are also used to compute values of self-produced goods, when a price is not available for the same household. For self-produced items, it would be ideal to use farm-gate prices, that would more precisely estimate their value. Market prices include the intermediaries' markup in the purchasing price. However, given the small size of the country and its relative degree of closeness to international market, it is reasonable to assume that observed food prices are close to farm-gate prices, since throughout the country there is a large availability of locally produced produce markets.

We consider prices as exogenous. Nevertheless, the program could influence household decisions not only directly, but indirectly through prices, if the amount of money distributed by the program was large enough to have an effect on the demand for food in local markets. However, it is reasonable to believe that the program had little effect on local prices since the total amount transferred is relatively small, and the CCT program is targeting only a small part of the population. In addition, we expect to observe little geographical variation on non-durables' prices, again because of the small size of the country. 


\section{Empirical strategy}

The main goal of this paper is to study the effects of targeting resources to mothers rather tha household heads on the structure of household expenditures. We use two complementary empirical approaches. First, we estimate the effect of targeting payments to women on expenditure shares. This analysis does not require modelling individual behaviour; instead it can rely entirely on the variation induced by the randomization, and the comparison of expenditure shares in the different groups of municipalities. Second, we estimate a demand system and examine how the parameters of the system are affected by the intervention. This part of the analysis requires the specification and identification of an economic model of individual behaviour, which can be informative about the mechanisms that determine the impacts of the programme on expenditure shares.

\subsection{Expenditure shares}

Since we are interested in understanding how the gender of the recipient of the transfer affects the way households allocate expenditures, we start by looking at intent-to-treat (ITT) estimates of the impact of gender-targeting on expenditure shares. We do so by comparing outcomes between municipalities grouped in different payment modalities. The design of the intervention, characterized by a randomization of the treatment modality at municipality level, allows for a simple comparison between households in municipalities where mothers are the recipients (which we will call "Mother municipality"), and municipalities where the household heads are the recipients of the transfer (which we will call "HH municipality").

As we discuss below, the fact that a household lives in a Mother municipality, does not guarantee that the woman in that household actually receives the transfer, e.g. because the household does not take up the program. For this reason, the estimates that we obtain comparing the two groups of municipalities are ITT estimates.

Let mother $_{j}$ be an indicator variable equal to 1 if municipality $j$ is a Mother municipality, and zero otherwise, and denote $w_{i j}$ as an outcome of interest for household $i$ in municipality $j$ (e.g. the share of total expenditure spent on food). To measure the effect on $w_{i j}$ of targeting the transfer to mothers versus household heads we estimate the following relationship:

$$
w_{i j}=\beta_{0}+\beta_{1} \text { mother }_{j}+X_{i}^{\prime} \beta_{\mathbf{2}}+V_{j}^{\prime} \beta_{\mathbf{3}}+\epsilon_{i j}
$$

where $X_{i}$ is a vector of household characteristics, $V_{j}$ is a vector of municipality characteristics, and $\epsilon_{i j}$ is an household-specific error term. We cluster the standard errors at the level of the municipality. Household controls include the education of the household head, age and gender of the head, ethnicity, size, and household composition. Municipality controls include regional dummies, as well as indicators for whether the municipality is rural, and for whether the household lives in the capital city. 


\subsection{Demand system}

To study the effect of gender-targeted cash transfers on household decision making, we estimate a household demand model. This is useful since the CCT program could shift the decision to allocate expenditure towards different resources not only through the control of the transfer, but also through its potential effect on total household expenditure. In other words, we study whether the program's payment modalities induce a shift in the Engel curve (which could operate through its intercept or its curvature), a shift along the Engel curve, or both.

Since the main effect captured by ITT estimates is on food share, we first estimate a demand equation for food using the Almost Ideal Demand System (Deaton and Muellbauer, 1980). We have also experimented with the Quadratic Almost Ideal Demand system (Banks et al., 1997). However, the coefficient on the quadratic term of total expenditure is rarely significant, suggesting a linear relationship between the budget share and total expenditure for the sample analysed. The model we estimate is the following:

$$
\begin{aligned}
w_{i j}^{F O O D}= & \beta_{0}+\beta_{1} \text { tmother }_{i j}+\delta \ln \left(\frac{\exp _{i j}}{a(p)}\right)+\eta \ln \left(\frac{\exp _{i j}}{a(p)}\right) * \text { tmother }_{i j}+ \\
& +\sum_{n=1}^{N} \gamma_{i j n} \ln \left(p_{n j}\right)+X_{i}^{\prime} \beta_{\mathbf{2}}+V_{j}^{\prime} \beta_{\mathbf{3}}+\epsilon_{i j}
\end{aligned}
$$

where $w_{i j}^{F O O D}$ is expenditure share spent on food, $\exp _{i j}$ is total household expenditure on nondurables, $a(p)$ is a price index and $p_{n j}$ is the price of item $n$ in municipality $j$. Similar to the previous specification, $X_{i}$ is a vector of household characteristics, $V_{j}$ is a vector of municipality characteristics, and $\epsilon_{i j}$ is a household-specific error term, which we assume to be clustered at the municipality level.

The variable tmother $_{i j}$ is an indicator for whether a CCT transfer was received by the mother in household $i$, residing in municipality $j$. This variable is equal to one if the household applied for the program and resides in a municipality where the payment is given to the mother, or if the head of the household is a mother. This variable is equal to zero otherwise. We will also present models where we replace tmother ${ }_{i j}$ by mother ${ }_{j}$. We allow the slope of the Engel curves to vary with the type of municipality, by interacting the expenditure terms with tmother $_{i j}$.

Using equation (2), we can therefore analyse not only how the budget share of food shifts when the CCT targeted mothers, but also how this change relates to different total expenditures. Since prices are not available for non-food items, we can estimate the demand equation only controlling for the food price index, as defined in Section 3.2.2.

In order to understand whether payments to the mother change the allocation of food expenditures across items, we also extend our analysis to the demand within the food basket. In particular, 
we estimate the following demand system:

$$
\begin{aligned}
w_{i j}^{m}= & \beta_{0, m}+\beta_{1, m} \text { tmother }_{i j}+\delta_{m} \ln \left(\frac{\exp _{i j}^{F O O D}}{a(p)}\right)+\eta_{m} \ln \left(\frac{\exp _{i j}^{F O O D}}{a(p)}\right) * \text { tmother }_{i j}+ \\
& +\sum_{m=1}^{M} \gamma_{i j m} \ln \left(p_{m j}\right)+X_{i}^{\prime} \beta_{\mathbf{2}, \mathbf{m}}+V_{j}^{\prime} \beta_{\mathbf{3}, \mathbf{m}}+\epsilon_{i j m}
\end{aligned}
$$

where $w_{i j}^{m}$ is the share of food expenditure allocated to food category $m, \exp _{i j}^{F O O D}$ is food expenditure, $a(p)$ is a price index and $p_{m j}$ is the price of item $m$ in municipality $j$. Equation (3) is estimated for each of the food categories in a demand system where $\epsilon_{i j m}$ is a household-specific and item-specific error term, which we assume to be clustered at municipality level and to be correlated across equations.

In estimating the demand system, we take into account the fact that several variables on the right hand side of equations (2) and (3) are potentially endogenous, i.e., they correlate with the residuals of the equations. This is potentially an issue for total expenditure (either because of the presence of measurement error or because of taste heterogeneity), for schooling choices (as they are probably jointly determined with expenditure), and for the actual receipt of the transfer by the wife (which is affected by program take-up and is therefore also a choice).

We tackle this issue using a control function approach, which consists in adding to the estimating equation an approximation to the conditional mean of the residuals, given the endogenous variables. In order to implement we first estimate first stage regressions of the endogenous variables on the exogenous variables in the model, including exclusion restrictions for each endogenous variable. We then compute the residuals of these first stage models, and incorporate functions of these residuals as regressors in equations (2) and (3) (the control function). The main reason to consider a control function approach is the possibility to allow interactions between endogenous variables (i.e., estimate a non-linear model with endogenous regressors), which is particularly important since the objective of the paper is to identify not only a shift in the intercept of the Engel curves induced by gender-targeted transfers, but also changes in their slopes.

The exact form of the control function depends on the specific assumptions one makes about the probability distribution of the residuals of all the model's equations. We approximate these unknown functions with second-order polynomials in the residuals: we therefore add to each demand equation the residuals, their squares and their interactions. The control function approach also gives a straightforward test for endogeneity, by testing the significance of the control functions in the estimating equations. We perform a regression-based Hausman test to test for endogeneity of the selected endogenous control variables, computed as a joint Wald test for the equality to zero of all coefficients in the polynomial of residuals. Standard errors are estimated using a bootstrap estimator allowing for clustering at municipality level to account for the correlation between households living in the same location and same treatment unit.

We consider three sources of endogeneity in our demand system: the actual CCT transfer to 
a mother, the endogeneity of total expenditure and of schooling decisions. In order to achieve identification in the control function approach, we need to assume exclusion restrictions for each instrument. In other words, each instrument must affect the share equation only through the endogenous variable and not directly.

Whether a wife actually receives the transfer depends, by definition, on whether a household lives in a Mother or a HH municipality. It also depends on whether the household takes up the program and who is declared as a head of household. It is possible, for instance, that in a $\mathrm{HH}$ municipality the transfer is given to the mother if she is declared as head of household. We use the randomisation as the identifying restriction of this type of endogeneity.

The second source of endogeneity in the demand system arises because total expenditure might be endogenous. As is common in this literature, we use information about wealth as an identifying instrument for total expenditure.

The final source of endogeneity we consider is that of school choices. Whilst it is important for us to control for schooling, as it is one of the conditionalities imposed by the program, we recognise that these choices can be correlated with expenditure decisions. As instruments for this choice we use the gender of the first born child and the expected probability (as expressed by the parents) that the child will attend university.

We discuss in detail the endogeneity issues, the control function procedure, and the instruments we have used in Appendix A.1, where we also present the results of the first stage of our demand system.

\section{Results}

In this section we focus on intent-to-treat estimates of the impact of targeting CCTs to mothers on household expenditure, on expenditure shares and on the share of food expenditure allocated to different food categories. We estimate the two demand systems using a sample of around 800 households and using information collected during the follow-up survey in 2012.

\subsection{Impacts on expenditure shares}

We first analyse how targeting payments to mothers affects the consumption of household living in different municipalities. Columns 1-2, and columns 5-6 in Table 4, present means and standard deviations for total household expenditure on non-durables, for the value of households' durables, and for expenditure shares, at baseline and follow-up, respectively. Columns 3 and 7 present a simple mean difference between the two groups at baseline and follow-up, while columns 4 and 8 present these differences, estimated after accounting for demographic controls.

When looking at total expenditure on non-durables, we do not observe significant differences between households in the two groups of municipalities, neither at baseline, nor at follow-up. This is an expected result, since the program did not introduce a pure control group of municipalities, i.e. the CCT transfer is potentially offered to every eligible household in the country. 
Figure 1: Non-parametric distribution fit for food budget shares at baseline and follow-up
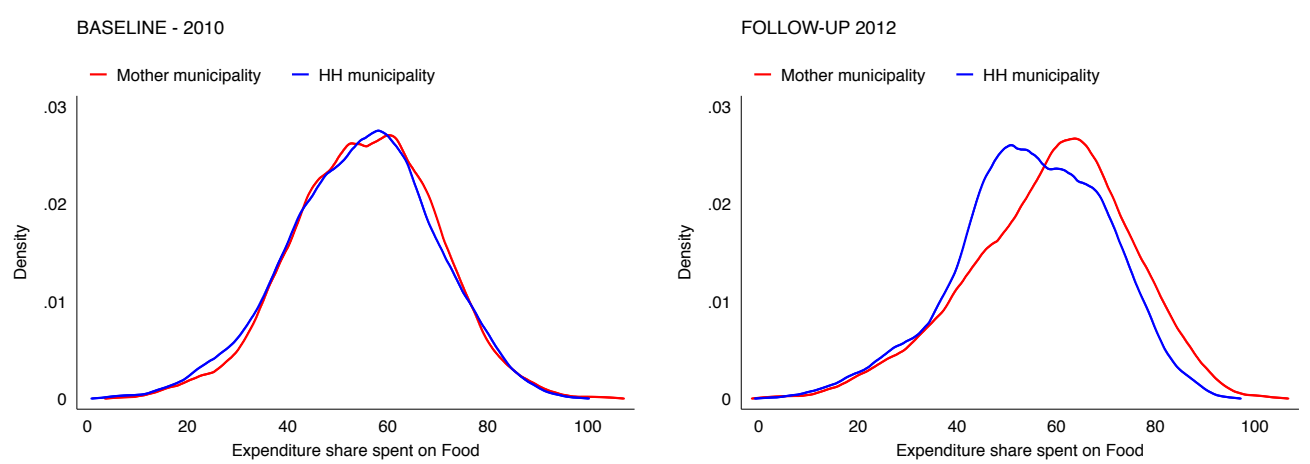

Note. The distribution fit is estimated non-parametrically using a Kernel density. The left panel shows the comparison between Mother and $\mathrm{HH}$ municipalities at baseline, while the right panel shows the same comparison at follow-up. A two-sample Kolmogorov-Smirnov test statistic is equal to 0.04 at baseline (p-value for equality of distributions equal to 0.79 ) and to 0.16 at follow-up (p-value $<0.01$ ).

More interestingly, the gender of the recipient of the CCT seems to have affected the allocation of expenditure to different items. At follow-up, we find a statistically significant higher share of food of roughly $4-5 \%$, for households residing in municipalities where the mother is the recipient of the transfer. This difference is not present at baseline. This evidence therefore indicates that targeting mothers had a significant effect on the share of total expenditure allocated to food; consistent with the previous literature, it seems to increase it. In addition, we observe a marginally significant decrease in the expenditure shares of clothing and of tobacco and alcohol, although these results become statistically insignificant when we add controls to the model.

The effect on expenditure shares might be observed due to an increase in the allocated resources to a certain consumption good or because the household might start purchasing it. In both cases we would observe an increase in the budget share. To disentangle these effects, we look at the share of non-zero consumption for each item. In Appendix B.3, we find no significant effects on the proportion of non-zero expenditures, suggesting that the change in food shares is driven by an increase in its expenditure share.

Figure 1 presents the Kernel density for the food budget share at baseline and follow-up in the two groups of municipalities: those where the mother receives the transfer, and those where it is paid to the household head. At baseline, the distributions of food shares in the two samples are statistically identical; we cannot reject the null of equality of the two distributions using a twosample Kolmogorov-Smirnov (KS) test for either food shares or total expenditure. In Appendix A.1.2 we present similar evidence for the distribution of total expenditure at baseline. At followup, we observe that the distribution of food budget shares for municipalities where the transfer is targeted at women is entirely shifted to the right relative to the distribution in other municipalities. A KS test rejects the null of equality of the distributions in the two samples. The main drivers of this difference are households allocating more than $35 \%$ of total expenditure to food.

Since we observe a robust effect of the identity of transfer recipient on food expenditure shares, we next investigate the allocation of food expenditures within the food basket. Columns 1-2, 


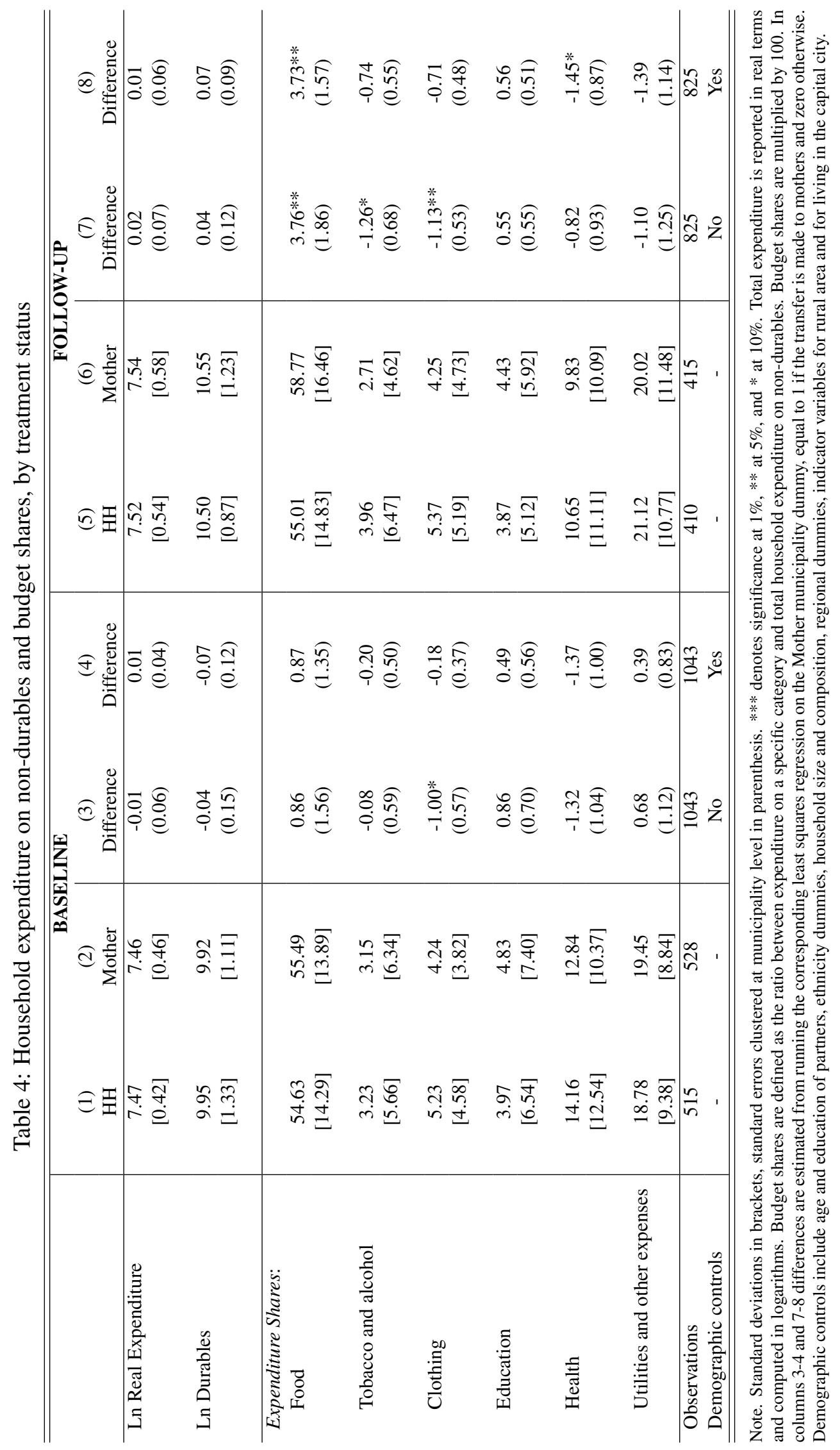


and columns 5-6 in Table 5, present means and standard deviations for the proportion of food expenditure in different food items, at baseline and follow-up, respectively. Columns 3 and 7 present a simple mean difference between the two groups at baseline and follow-up, while columns 4 and 8 present these differences estimated after accounting for demographic controls. Columns 7 8 show that, at follow up, we cannot detect any statistically significant effect on the way households allocate expenditures within the food basket. The result is consistent across different estimation methods. As expected, the same is true at baseline (see columns 3-4 of the table).

Changes in the control of household resources can plausibly affect both the level and the slope of the Engel curves. Therefore, it is interesting to examine not only the impact of such changes on expenditure shares, but also their impact on the Engel curve. We turn to this in the next section.

\subsection{Food Engel curve and the demand for food}

We begin by estimating an Engel curve for food using equation 2, taking into account the endogeneity of some of the variables on the right hand side by a control function approach (see section 4.2). The estimation results for the first stage of this system are discussed in Appendix A.1. We report the coefficient estimates in table 6 . In column 1, we estimate the impact of being assigned to a municipality where the mother is paid on the intercept of the Engel curve, while in column 2, we also interact this variable with household expenditure, thereby allowing it to affect the slope of the Engel curve as well. We observe that offering transfers to women shifts the intercept on the Engel curve by 4.13 percentage points. There is also a steepening of the Engel curve, but this change is not statistically significant.

In columns 3-4 of this table, we investigate the impacts on the Engel curve of the actual receipt of the transfer by a woman, i.e. we use an indicator for whether the woman received a transfer or not, instrumented with the type of municipality she resides in. When transfers were received by women in the household the intercept of the Engel curve shifted up by 5.6 percentage points, but again we do not observe a significant effect when we look at the change of the slope. ${ }^{9}$

Having established the impact of targeting transfers to women on food expenditure, we focus next on the components of the total food budget. Table 7 presents the estimated coefficients of demand system 3 for different items in the food basket. Similarly to the estimation of the Engel curve for food, columns 1-2 show the impacts of residing in a Mother municipality on the Engel curve, while columns 3-4 show the impacts of actual transfer receipt to a woman on the Engel curve. Figure 2 plots the Engel curves within the food basket using the estimated coefficients in column 2.

We observe statistically significant changes in either the intercepts or slopes of the Engel curves for all food categories except fruit and vegetables. This suggests that, while for food expenditures a shift in the slope of the Engel curve was not statistically important, this is not the case when we look within the food basket.

\footnotetext{
${ }^{9}$ In Appendix B.1 we discuss heterogeneity in the main effect of the program. We find that the effect is particularly strong for Muslim households, while there is no significant effect for non-Muslim.
} 


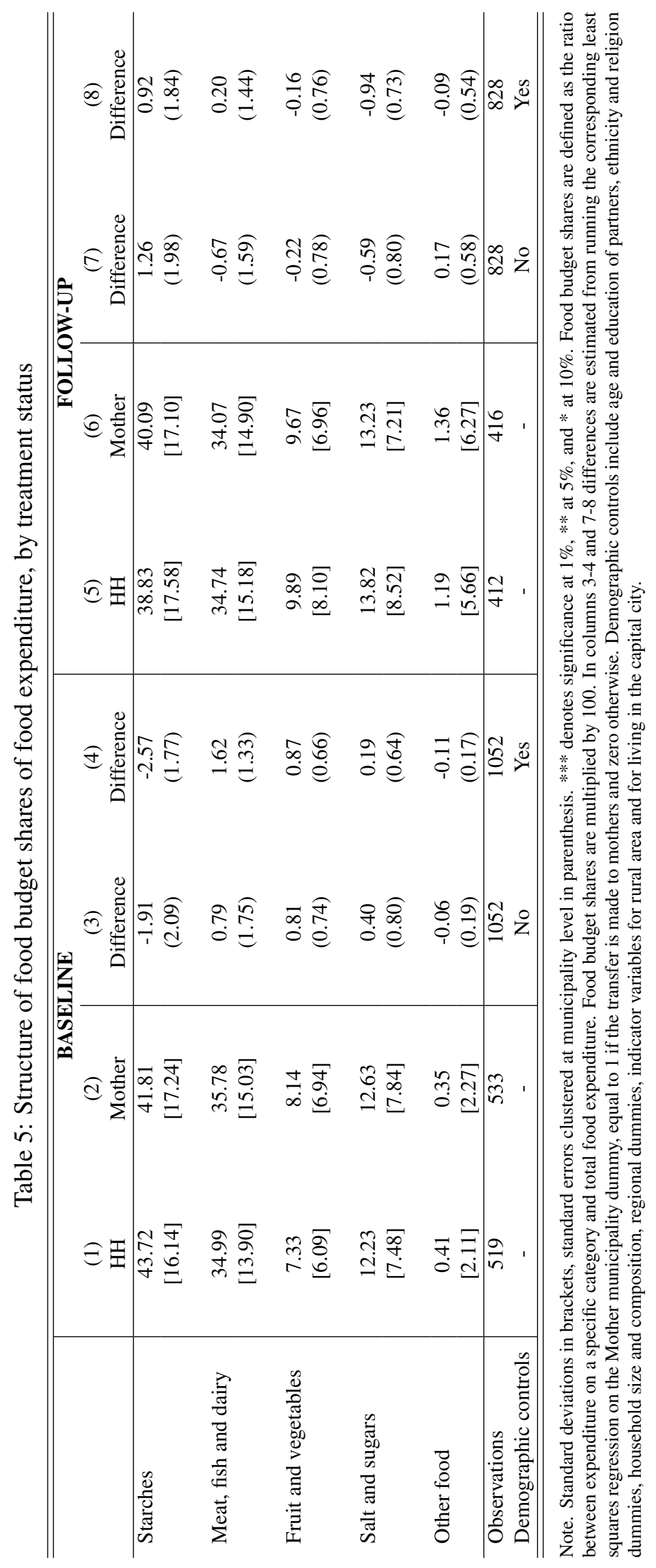


Table 6: Food Engel curve

\begin{tabular}{|c|c|c|c|c|}
\hline \multirow[b]{2}{*}{ Main: } & \multicolumn{4}{|c|}{ Dep.var.: Food budget share } \\
\hline & \multicolumn{2}{|c|}{ Mother Municipality } & \multicolumn{2}{|c|}{ Actual transfer to mother } \\
\hline & (1) & (2) & (3) & (4) \\
\hline \multirow[t]{2}{*}{ Mother } & $4.13 * * *$ & $4.15 * * *$ & $5.63 * * *$ & $5.63 * * *$ \\
\hline & $(1.54)$ & $(1.55)$ & $(2.00)$ & $(1.98)$ \\
\hline \multirow[t]{2}{*}{ Expenditure } & $-9.63 * * *$ & $-8.77 * *$ & $-9.37 * *$ & $-9.42 * *$ \\
\hline & $(3.68)$ & $(4.18)$ & $(3.72)$ & $(4.02)$ \\
\hline \multirow[t]{2}{*}{ Mother x Expenditure } & & -1.39 & & 0.14 \\
\hline & & $(2.92)$ & & $(3.63)$ \\
\hline Controls & Yes & Yes & Yes & Yes \\
\hline Observations & 811 & 811 & 811 & 811 \\
\hline$R^{2}$ & 0.232 & 0.232 & 0.234 & 0.234 \\
\hline $\begin{array}{l}\text { F-test for joint significance of main and } \\
\text { interaction ( } p \text {-value) }\end{array}$ & . & 0.01 & . & 0.01 \\
\hline Endogeneity test (p-value) & 0.00 & 0.00 & 0.00 & 0.00 \\
\hline
\end{tabular}

Note. Bootstrap standard errors clustered by municipality (2000 replications) are presented in parentheses. *** denotes significance at $1 \%$, ** at $5 \%$, and $*$ at $10 \%$. Dependent variable is the food budget share, defined as the ratio between the expenditure on food and the total household expenditure. "Expenditure" is the (demeaned) total household expenditure on non-durable. In columns 1-2, the main variable is the "Mother municipality" dummy variable, equal to 1 if the household resides in a Mother municipality and 0 otherwise. In columns 3-4, the main effect is a dummy variable equal to 1 if a woman received at least one payment during the first two years of the program and is instrumented using the "Mother municipality" dummy. Controls include age and education of partners, ethnicity dummies, household size and composition, regional dummies, indicator variables for rural area and for living in the capital city, food price control and the number of children enrolled in school. Endogenous variables are instrumented using a control function approach (see section 4.2). The endogeneity test is performed as a joint Wald test for the equality to zero of all coefficients in the polynomial of residuals.

Figure 2: Estimated Engel curves for food categories
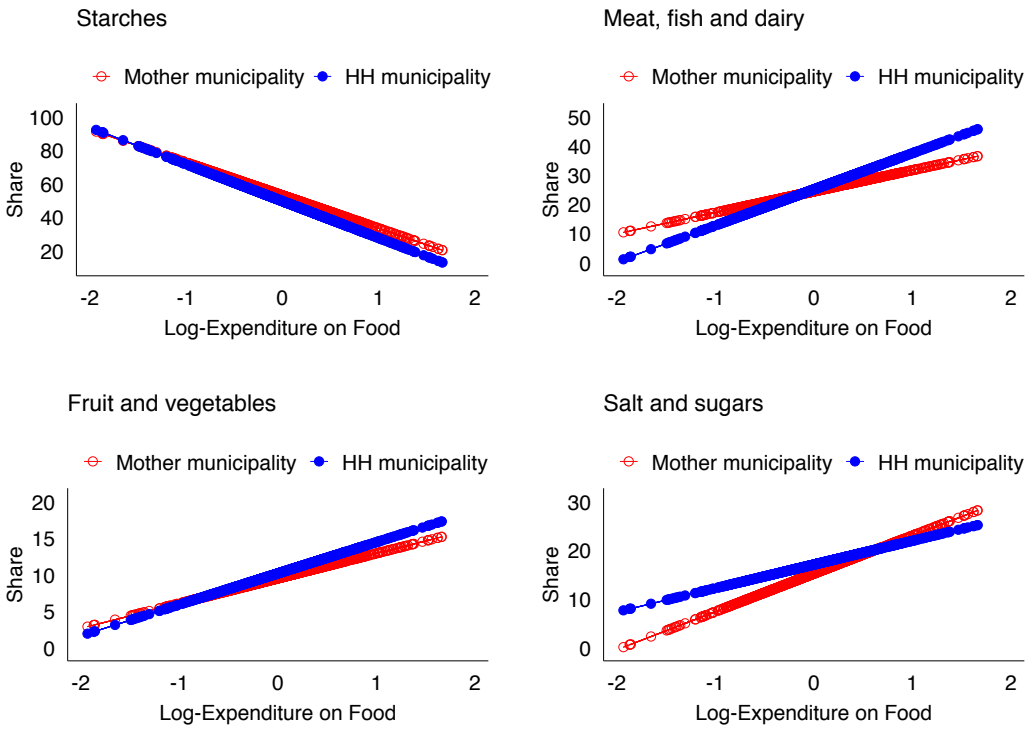

Note. The graphs present the estimated Engel curves (holding other control variables constant at the average) for food categories for households living in a Mother municipality and for households living in a HH municipality. Estimated coefficients are reported in column 2 of Table 7. Log-Expenditure on Food is demeaned.

In sum, in line with Engel's law, food is a necessity for these households: the share of expenditures allocated to food decreases as total expenditure increases. An increase by $9 \%$ in total 
Table 7: Demand system for the food basket

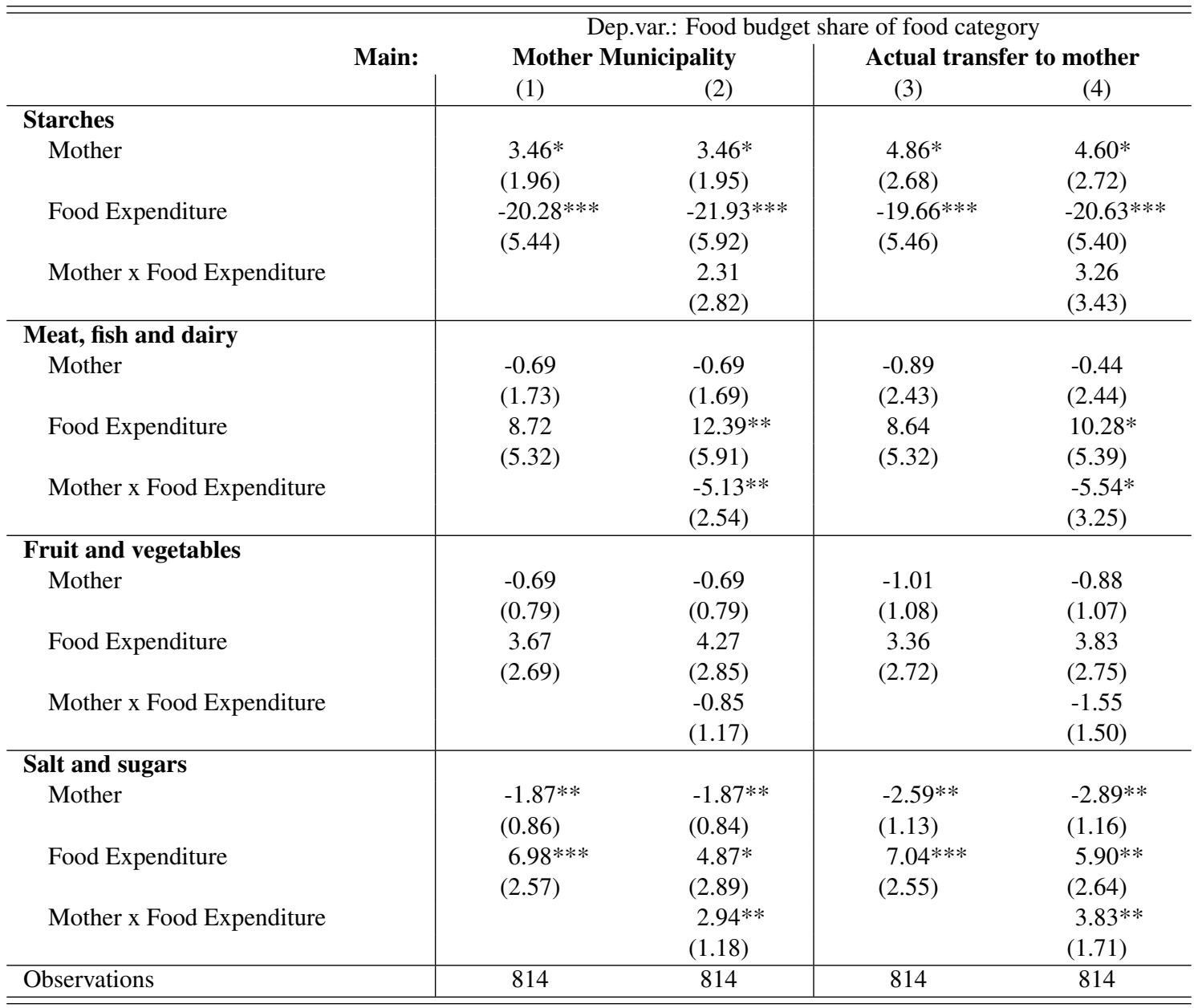

Note. Bootstrap standard errors clustered by municipality (2000 replications) are presented in parentheses. *** denotes significance at $1 \%, * *$ at $5 \%$, and * at $10 \%$. Dependent variables are the shares of food expenditure spent on each category. "Food Expenditure" is total (demeaned) food. In columns (1) and (2), the main variable is the "Mother municipality" dummy variable, equal to 1 if the household resides in a Mother municipality. In columns (3) and (4), the main effect is a dummy variable equal to 1 if a woman received at least one CCT payment and is instrumented using the "Mother municipality" dummy. Controls include age and education of partners, ethnicity dummies, household size and composition, regional dummies, indicator variables for rural area and for living in the capital city, food price control and the number of children enrolled in school. Endogenous variables are instrumented using a control function approach (see section 4.2).

expenditure is associated with a decrease of around $1 \%$ in the budget share spent on food. Our figures show that, within the food basket, targeting CCT payments to the mother in households with low levels of food expenditure (presumably, the poorest) induces a move away from salt and sugars, and towards meat, fish and dairy. This seems to suggest that, at least at low levels of food expenditure, there is a shift towards a more nutritious diet as a result of an increase in household resources controlled by women.

One potential driver of our results is that husbands and wives have different preferences, and that an increased control of household income by wives shifts the allocation of household income towards food and different types of food, presumably because women favour food expenditure abd specific food items more than men. 


\section{Conclusion}

Most social programs in the developing world support poor families with transfers that are mainly channelled to women. However, the effect of the provision of additional cash to one specific family member on the household consumption allocation is still unclear. One problem in the literature has been the lack of suitable data for this analysis, since most of these interventions have transferred their financial support uniquely in the hands of women, restricting the possibility of comparing outcomes for households where the transfer is exogenously provided to a different household member.

This paper studies the effect of a nationwide transfer program, the Macedonian CCT for Secondary School education. This program provided cash transfers to poor households in Macedonia conditional on having their children enrolled in secondary school. As the gender of the recipient was randomized across municipalities to be either transferred to the mother of the child or the household head, it deliberately changed the control of resources within households, increasing the share of total income controlled by the mother of the child.

When provided with an additional source of income, mothers and fathers spend income differently. We cannot exclude that the mechanism influencing household consumption behaviour is exclusively related to the control of resources. An additional mechanism could be related to a differential allocation of time that is affected by the gender of the recipient and that in turn changes consumption. To test this hypothesis, we collected information about the amount of time spent by both parents the day before the interview on different activities and we do not find any effect on the allocation of time. We discuss some of these issues in Appendix B.6.

We show that targeting cash transfers to women increases the share of resources allocated to food and has a significant impact on the shape of Engel curves for different food items. For lower levels of food expenditures, mothers tend to allocate more resources to meat, fish and dairy and less to salt and sugars. For higher levels of expenditures, this relationship is inverted (although less striking), with mothers allocating resources away from meat, fish and dairy and towards salt and sugars. 


\section{References}

Akresh, R., D. de Walque, and H. Kazianga (2012). Alternative cash transfer delivery mechanisms: Impacts on routine preventative health clinic visits in Burkina Faso. Working Paper 17785, National Bureau of Economic Research. 3

Angelucci, M. and O. Attanasio (2009). Oportunidades: program effect on consumption, low participation, and methodological issues. Economic development and cultural change 57(3), 479-506. 3

Angelucci, M. and O. Attanasio (2013). The demand for food of poor urban mexican households: Understanding policy impacts using structural models. American Economic Journal: Economic Policy 5(1), 146-205. 3

Angrist, J. D. and W. N. Evans (1998). Children and their parents' labor supply: Evidence from exogenous variation in family size. The American Economic Review 88(3), 450-477. 4

Attanasio, O., E. Battistin, and A. Mesnard (2012). Food and cash transfers: Evidence from Colombia. The Economic Journal 122(559), 92-124. 3

Attanasio, O. and V. Lechene (2010). Conditional cash transfers, women and the demand for food. IFS working papers (No. 10, 17). 2

Attanasio, O., V. D. Maro, V. Lechene, and D. Phillips (2013). Welfare consequences of food prices increases: Evidence from rural Mexico. Journal of Development Economics 104, 136151. 10,2

Banks, J., R. Blundell, and A. Lewbel (1997). Quadratic Engel curves and consumer demand. Review of Economics and Statistics 79(4), 527-539. 12

Benhassine, N., F. Devoto, E. Duflo, P. Dupas, and V. Pouliquen (2015). Turning a shove into a nudge? a "labeled cash transfer" for education. American Economic Journal: Economic Policy (7(3)), 86-125. 3

Bourguignon, F., M. Browning, P. Chiappori, and V. Lechene (1993). Intra-household allocation of consumption: a model and some evidence from French data. Annales d'Economie et de Statistique, 137-156. 2

Browning, M., F. Bourguignon, P. Chiappori, and V. Lechene (1994). Incomes and Outcomes: a Structural Model of Intra-Household Allocation. Journal of Political Economy 102(6), 10671096. 2

Dahl, G. B. and E. Moretti (2008). The demand for sons. The Review of Economic Studies 75(4), 1085-1120. 4 
Deaton, A. and J. Muellbauer (1980). An almost ideal demand system. The American Economic Review, 312-326. 12

Deaton, A. and S. Zaidi (2002). Guidelines for constructing consumption aggregates for welfare analysis. World Bank Publications. 7

Dunbar, G. R., A. Lewbel, and K. Pendakur (2013). Children's resources in collective households: identification, estimation, and an application to child poverty in Malawi. The American Economic Review 103(1), 438-471. 2

Phipps, S. and P. Burton (1998). What's mine is yours? The influence of male and female incomes on patterns of household expenditure. Economica 65(260), 599-613. 2

Schady, N. and J. Rosero (2008). Are cash transfers made to women spent like other sources of income? Economics Letters 101(3), 246-248. 3

Schultz, T. (1990). Testing the neoclassical model of family labor supply and fertility. The Journal of Human Resources 25(4), 599-634. 2

The World Bank (2009). Project appraisal document - report no: 47195-mk. Technical report, The World Bank and Former Yugoslav Republic of Macedonia. 4

Thomas, D. (1990). Intra-household resource allocation: An inferential approach. The Journal of Human Resources 25(4), 635-664. 2

Verme, P. (2008). A review of the social protection system in the Republic of Macedonia. Ministry of Labour and Social Policy, Republic of Macedonia. 4

Wooldridge, J. M. (2010). Econometric analysis of cross section and panel data. MIT press. 6, 5, 7,8 


\section{APPENDIX for "The Effect of Gender-Targeted Conditional Cash Transfers on Household Expenditures: Evidence from a Randomized Experiment"}

\section{A Demand equation estimation}

In this section we discuss in details the control function method adopted for the estimation of the demand equations.

Similarly to equations (2) and (3), let $w$ be the outcome variable (i.e. the expenditure share on a specific item), tmother an indicator for whether a CCT transfer was received by the mother in the household in the first two years of the program, $y_{3}$ the total expenditure (or total food expenditure) and $y_{4}$ the number of children enrolled in school. Assuming $\mathbf{z}$ is the $1 \times L$ vector of all exogenous variables (including a constant), we can write the following specification:

$$
w=\alpha_{2} \text { tmother }+\alpha_{3} y_{3}+\alpha_{4} y_{4}+\gamma_{1} \text { tmother } \cdot y_{3}+\mathbf{z}_{1} \delta_{1}+u_{1}
$$

where $\mathbf{z}_{\mathbf{1}}$ is a $1 \times L_{1}$ strict sub-vector of $\mathbf{z}$ such that $\mathbf{z}=\left[\begin{array}{ll}\mathbf{z}_{\mathbf{1}} & \mathbf{z}_{-\mathbf{1}}\end{array}\right]$ and $\mathbf{z}_{-\mathbf{1}}$ is the $1 \times\left(L-L_{1}\right)$ vector of excluded instruments. To identify the parameters of interest, we need to address the endogeneity of the variables tmother, $y_{3}$ and $y_{4}$. We follow a control function approach and we instrument endogenous variables with $\mathbf{z}_{-\mathbf{1}}$, which we discuss in detail in the next section. The control function approach is also followed since the model presents non-linearities in endogenous variables, including interactions between endogenous variables.

\section{A.1 First stage of the demand system}

\section{A.1.1 Actual transfer to a mother}

Among the potential recipients initially sampled, around 70\% received at least one CCT payment in the first two years of the program, showing that a share of potential recipients decided to not enrol in the program. In addition, the actual transfer to a mother is also affected by the choice of who within the household is declared as head. In municipalities where the transfer is targeted to household heads, the actual transfer is received by a mother if at the same time she is the household head. This is clearly not exogenous, but driven by a specific decision process that is not observed. However, it is reasonable to believe that the program did not induce changes in household headship, since this decision occurred prior to the introduction of the CCT, and is related to the application to the SFA program, a pre-condition to enrol in the CCT program.

To instrument for the endogenous receipt of the transfer by a mother, we use the indicator variable for treatment modality at municipality level, mother $r_{j}$, as instrument. Since payment modalities are defined through a lottery, this variable provides exogenous variation in the probability of a mother to receive a payment.

Columns 1 and 5 in table A1 presents first stage regressions of program take-up (tmother) on 
the instruments based on the following specification estimated via Maximum Likelihood:

$$
\text { tmother }=\mathbb{1}\left[\mathbf{z} \delta_{2}+e_{2} \geq 0\right]
$$

where the error term $e_{2} \sim \operatorname{Normal}(0,1)$ and $E\left[\mathbf{z}^{\prime} e_{2}\right]=0$. Column 1 refers to the estimation of food demand and column 5 refers to the demand system for food categories. We show a strong relationship between residing in a mother municipality and observing a woman having received a CCT transfer. ${ }^{2}$ Using a linear probability model (columns 2 and 6) supports the same conclusion.

\section{A.1.2 Endogenous Expenditure}

A second source of endogeneity arises from the inclusion of expenditure in the estimating equations. If total expenditure and total food expenditure are subject to measurement error, or if they are correlated with unobserved preference shocks, then it is important to address these issues in order to identify the slope of the Engel curve (Attanasio et al., 2013; Attanasio and Lechene, 2010).

We instrument total expenditure and food expenditure using information about wealth. Wealth measures are standard instruments for expenditure in demand estimation (see, for example, Dunbar et al., 2013). They can be considered valid instruments if consumption allocation decisions within a period are separable from savings decisions across periods (and if recall error in wealth is uncorrelated with recall error in consumption).

We use the value of durable goods and the land owned by the household as measures of wealth. Durable goods are enumerated during the interview using a list of 25 items, including household appliances, communication and entertainment appliances and vehicles. The value of durable goods is self-reported by the respondent for each item by answering the question "Imagine you find similar items at the local market or shop. How much would you have to pay to purchase them?". Table A1 shows first stage results of a linear regression of total expenditure on the instruments using the following linear specification:

$$
y_{3}=\mathbf{z} \delta_{3}+e_{3}
$$

where $E\left[\mathbf{z}^{\prime} e_{3}\right]=0$. Column 3 reports the results for total expenditure on non-durables, while column 7 show the results for food expenditure. For total expenditure we include a quadratic term for the durables, while we exclude it in the food expenditure regression since it is not significant. The partial F-statistic on the instruments is high for both endogenous variables.

Total expenditure and wealth are both balanced at baseline. Figure A1 presents the distributions of the total household (log-)expenditure and of wealth for households living in Mother and

\footnotetext{
${ }^{2}$ Since the CCT system is implemented on the family structure from the SFA system, it is rare to observe a payment targeted at the wrong person. In administrative data, less than $1 \%$ of payments is processed to a man (conditional on the mother being present) in a Mother municipality. This is possibly due to mistakes in the original SFA database.

${ }^{3}$ We alternatively implement a measure of durables by imputing the value of each good within each household using median unit values at regional level (or for the whole country), and an asset index built solely on whether the household own one or more item. The choice of the measure do not affect our results.
} 





HH municipalities. A Kolmogorov-Smirnov test for these variables cannot reject the equality of the distributions.

Figure A1: Non-parametric distribution fit for total household expenditure and durables at baseline
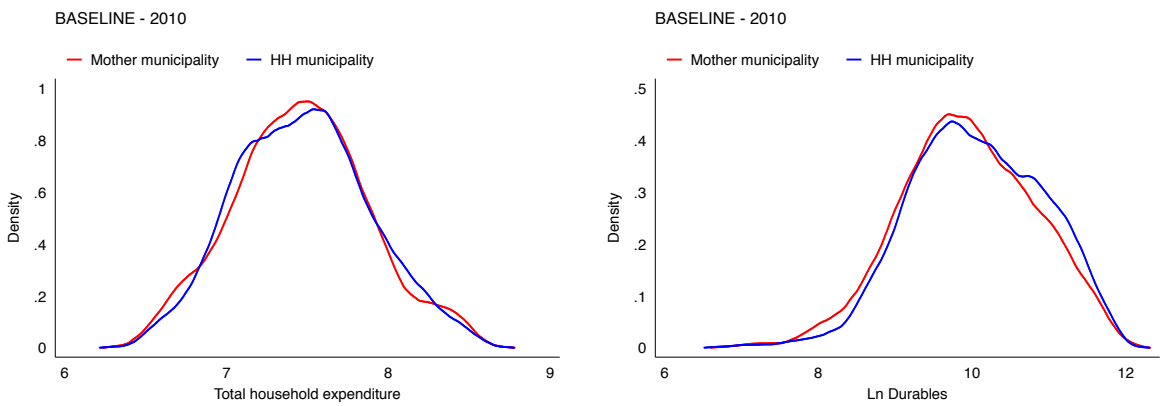

Note. The distribution fit is estimated non-parametrically using a Kernel density. The figure shows the comparison between Mother and Household Head municipalities at baseline for total household (log-)expenditure (left panel) and for the value of durables (right panel).

\section{A.1.3 Schooling endogeneity}

The CCT program provides payments conditional on children attending $85 \%$ of the classes. School attendance could have an impact on the consumption behaviour of households if, for example, it leads to education-related expenses. It is then important to control for household structure, and for the number of children enrolled in school. However, schooling decisions are potentially related with other household unobservable characteristics that can also affect food consumption. We instrument the number of children enrolled in school in each household using the gender of the first born child, and the expected probability (as expressed by parents) that children will attend university.

A large body of evidence uses the gender of the first-born as exogenous source of variation in household composition and relates it to different outcomes related to family decisions, such as fertility or child investment (Angrist and Evans, 1998; Dahl and Moretti, 2008). In Macedonia, while the vast majority of children attend primary school, female children among SFA recipients tend to have a higher enrolment rate in secondary school compared to male children. If, after controlling for the number of children, the first born is male, we should expect a lower number of children enrolled in school. Furthermore, after controlling for the number of children in the household, we do not expect a large effect of gender composition on expenditures.

The expected probability of attending university is also likely to be correlated with schooling decisions. ${ }^{4}$ The danger is that it could also be correlated with other unobservable household attributes that affect expenditures other than through schooling. Our assumption is that this is not the case conditional on the detailed set of controls adopted in our models.

\footnotetext{
${ }^{4}$ The probability is reported by the respondent during the interview on a scale from 0 to 10 . The information is asked for the two youngest adolescents aged 12-16 with different gender. Only one is asked otherwise. We report this information at household level by computing the average across available information for the household.
} 
Columns 4 and 8 of Table A1 show first stage results for the following linear regression of the number of children enrolled in school on the instruments:

$$
y_{4}=\mathbf{z} \delta_{4}+e_{4}
$$

where $E\left[\mathbf{z}^{\prime} e_{4}\right]=0$. The perceived probability that children will attend university increases the number of children enrolled in school. Furthermore, if the first born child is male, then this number decreases. The partial F-statistic on the instruments is high.

\section{A.2 Control function estimates}

To compute control function estimates, we start from equation (4) and we write the projection of the error term $u_{1}$ on a function $f$ of $\left(e_{2}, e_{3}, e_{4}\right)$ :

$$
u_{1}=f\left(e_{2}, e_{3}, e_{4}\right)+e_{1}
$$

where by construction $E\left[e_{2}^{\prime} e_{1}\right]=0, E\left[e_{3}^{\prime} e_{1}\right]=0$ and $E\left[e_{4}^{\prime} e_{1}\right]=0$. To allow for a flexible form, we approximate $f($.$) with a non-linear function in the first-stage residuals, specifically a$ second-order polynomial:

$$
f\left(e_{2}, e_{3}, e_{4}\right)=\rho_{2} e_{2}+\rho_{3} e_{3}+\rho_{4} e_{4}+\rho_{5} e_{2}^{2}+\rho_{6} e_{3}^{2}+\rho_{7} e_{4}^{2}+\rho_{8} e_{2} e_{3}+\rho_{9} e_{3} e_{4}+\rho_{10} e_{2} e_{4}
$$

In line with a control function standard approach (Wooldridge, 2010), we assume that, once conditioning for all endogenous and exogenous variables, the expected value of the error term $e_{1}$ is equal to $f($.$) , i.e. E\left[u_{1} \mid\right.$ tmother $\left., y_{3}, y_{4}, \mathbf{z}\right]=f\left(e_{2}, e_{3}, e_{4}\right)$. This is equivalent to assume that once conditioning for the first stage residuals, the expected value of $e_{1}$ is equal to zero. Therefore, to compute the control function estimates for equation (4), we first derive the first stage residuals from equations (5), (6) and (7) and we substitute for $u_{1}$ in equation 4 by writing:

$$
w=\alpha_{2} \text { tmother }+\alpha_{3} y_{3}+\alpha_{4} y_{4}+\gamma_{1} \text { tmother } \cdot y_{3}+\mathbf{z}_{1} \delta_{1}+f\left(\hat{e}_{2}, \hat{e}_{3}, \hat{e}_{4}\right)+e_{1}
$$

where $\hat{e}_{2}=$ tmother $\cdot \lambda\left(\mathbf{z} \hat{\delta}_{2}\right)-(1-$ tmother $) \cdot \lambda\left(-\mathbf{z} \hat{\delta}_{2}\right), \hat{e}_{3}=y_{3}-\mathbf{z} \hat{\delta}_{3}, \hat{e}_{4}=y_{4}-\mathbf{z} \hat{\delta}_{4}$ and $\lambda($.$) is the inverse Mills ratio. The new error e_{1}$ is uncorrelated not only with all endogenous variables (tmother, $y_{3}$ and $y_{4}$ ) but also with $e_{2}, e_{3}, e_{4}$ and $\mathbf{z}$. Under the specified hypothesis, OLS estimators for for $\alpha_{2}, \alpha_{3}, \alpha_{4}$ and $\gamma_{1}$ in equation (9) are consistent. Standard errors are estimated using a bootstrap estimator allowing for clustering at municipality level to account for the correlation between households living in the same location and same treatment unit.

We also present results when substituting tmother with the exogenous payment modality dummy, mother. In this case, the variable is treated as exogenous and the estimation is based on a similar procedure, but assuming that $f($.$) is only function of e_{3}$ and $e_{4}$. 


\section{B Additional analysis}

\section{B.1 Impact heterogeneity}

A natural variation in the effect of the CCT program is related to social norms, and specifically to religion. In Macedonia, the most common religion is Orthodox Christianity, which is practised mainly by ethnic Macedonians and it is the religion of the majority of the population. Islam is the second most diffused religion and has had a significant impact in the society due to the five centuries under the domination of the Ottoman Empire, starting from the end of the 14th century. It is practised mainly ethnic Albanians and Turks and it is representing around 33\% of the population. ${ }^{5}$ A minority of the population is also practising Catholicism, Protestantism, and Judaism.

In our sample, around 55\% of households are Muslim. We look at differences in the impact of the program by selecting Muslim versus non-Muslim households (mainly Orthodox Christian). While these two groups are comparable on most observable characteristics, Muslim households are in general less educated (mothers have on average 6 years of education compared to 8 for nonMuslim and fathers have 8 years of schooling in both groups) and family size is larger (4 members versus 5), which makes them slightly poorer in per-capita terms.

Table B2 presents the estimated coefficients for the food Engel curve, where columns 1-2 refers to Muslim households and 3-4 to non-Muslim households. We can observe that the slopes of the Engel curve for Muslim households is steeper than for non-Muslim households and we find a significant intercept effect for Muslim households. For non-Muslim households we find that providing transfers to women do not affect the household allocation to consumption to food.

Table B2: Heterogeneous treatment effect by household composition and religion

\begin{tabular}{|c|c|c|c|c|c|}
\hline & \multirow[b]{3}{*}{ Main: } & \multicolumn{4}{|c|}{ Dep.var.: Food budget share } \\
\hline & & \multicolumn{2}{|c|}{ MUSLIM HOUSEHOLDS } & \multicolumn{2}{|c|}{ NON-MUSLIM HOUSEHOLDS } \\
\hline & & $\begin{array}{c}\text { Mother } \\
\text { Municipality } \\
\text { (1) }\end{array}$ & $\begin{array}{l}\text { Actual transfer } \\
\text { to mother } \\
\text { (2) }\end{array}$ & $\begin{array}{c}\text { Mother } \\
\text { Municipality } \\
\text { (3) }\end{array}$ & $\begin{array}{l}\text { Actual transfer } \\
\text { to mother } \\
\text { (4) }\end{array}$ \\
\hline Main & & $\begin{array}{l}5.35^{* * *} \\
(2.25)\end{array}$ & $\begin{array}{l}8.14 * * * \\
(3.13)\end{array}$ & $\begin{array}{c}0.53 \\
(1.96)\end{array}$ & $\begin{array}{c}1.03 \\
(2.71)\end{array}$ \\
\hline Expenditure & & $\begin{array}{l}-11.80 * * \\
(5.23)\end{array}$ & $\begin{array}{l}-11.56^{* * *} \\
(5.26)\end{array}$ & $\begin{array}{l}-3.17 \\
(5.31)\end{array}$ & $\begin{array}{l}-3.38 \\
(5.38)\end{array}$ \\
\hline Controls & & Yes & Yes & Yes & Yes \\
\hline $\begin{array}{l}\text { Observations } \\
R^{2}\end{array}$ & & $\begin{array}{c}484 \\
0.200 \\
\end{array}$ & $\begin{array}{c}484 \\
0.213 \\
\end{array}$ & $\begin{array}{c}327 \\
0.272 \\
\end{array}$ & $\begin{array}{c}327 \\
0.275 \\
\end{array}$ \\
\hline
\end{tabular}

Note. Bootstrap standard errors clustered by municipality (2000 replications) are presented in parentheses. *** denotes significance at $1 \%, * *$ at $5 \%$, and $*$ at $10 \%$. Dependent variable is the food budget share, defined as the ratio between the expenditure on food and the total household expenditure. In columns 1 and 3, the main variable is the "Mother municipality" dummy variable, equal to 1 if the household resides in Mother municipality. In columns 2 and 4, the main effect is a dummy variable equal to 1 if a woman received at least one payment during the first two years of the program and is instrumented using the "Mother municipality" dummy as instrument. Controls include age and education of partners, ethnicity dummies, household size and composition, regional dummies, indicator variables for rural area and for capital city, food price control and for the number of children enrolled in school. Endogenous variables are instrumented according to Table A1.

\footnotetext{
${ }^{5}$ This percentage is only an approximation, since the latest available official figure is from the 2002 Census run the Macedonian State Statistical Office.
} 


\section{B.2 Attrition and sample selection}

We present an analysis of attrition rate at follow-up from baseline household. Table B3 presents probit regressions of attrition at follow-up under different specifications. The dependent variable is equal to one if the household was interviewed at baseline and was not re-interviewed at followup and zero if the household was interviewed at baseline and follow-up. In columns 1-2, we focus on all eligible households at baseline. On average women living in Mother municipality have a slightly higher probability to not respond at follow-up, but this difference is not statistically significant. Since at follow-up we are selecting only eligible households at the time of the interview, in columns 3-4 we restrict the sample to households with younger children eligible at baseline (with at least one child aged 14 to 16). The coefficient on being in a mother municipality is not driving the attrition rate. Both results suggest that sample selection at follow-up is not driving the results.

Table B3: Probability of attrition at follow-up

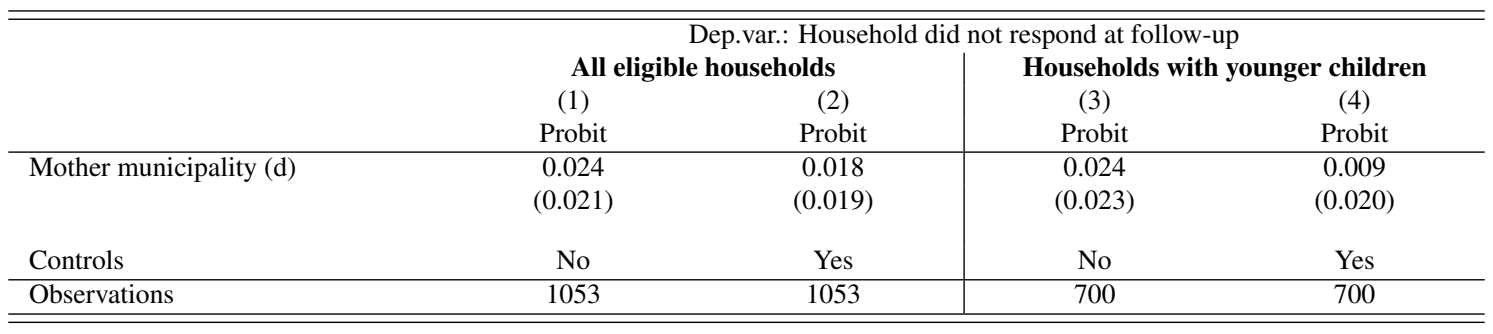

Note. Marginal effects. Standard deviations in brackets, standard errors in parenthesis. *** denotes significance at $1 \%$, ** at $5 \%$, and $*$ at $10 \%$. The dependent variable is equal to one if the household was interviewed at baseline and was not re-interviewed at follow-up and zero if the household was interviewed at baseline and follow-up. Columns 1-2 estimate a probit model using all eligible households at baseline, while columns 3-4 we restrict the sample to baseline households with younger children eligible (with at least one child aged 14 to 16 at baseline).

We then study the effect of targeting payments to mothers on the food budget share (equation 1) under different samples (table B4). Firstly, balance at baseline is not driven by sample selection. Column 1 compares food budget shares among all eligible households at baseline between households living in Mother and HH municipalities. Column 2 presents estimates of the same comparison, but restricting to households with at least one child aged 14 to 16 . There are no significant differences among these group of households. Secondly, the effect at follow-up is robust to selection on different sub-samples. Column 3 presents estimates for equation (1) using all eligible households (including the refresher sample), while column 4 restricts the estimation to only households interviewed at baseline. Restricting the sample does not affect our estimates. Thirdly, to control for robustness of the results to attrition, column 5 presents estimates for equation (1) using inverse probability weighting (Wooldridge, 2010), which allows increasing the weight of observations which had a higher attrition rate at follow-up. ${ }^{6}$ Results are robust to inverse probability weighting, suggesting attrition is not driving the results.

\footnotetext{
${ }^{6}$ The weights are generated using a Probit regression of an indicator variable being equal to 1 if the observation was interviewed at baseline, but was missing at follow-up (see column 2 in Table B3). From the regression, weights are computed by taking the inverse of one minus the predicted probabilities.
} 
Table B4: Treatment effect on food budget share under different sub-samples

\begin{tabular}{|c|c|c|c|c|c|}
\hline & \multicolumn{5}{|c|}{ Dep.var.: Food budget share } \\
\hline & \multicolumn{2}{|c|}{ BASELINE } & \multicolumn{3}{|c|}{ FOLLOW-UP } \\
\hline & $\begin{array}{c}\text { All eligible } \\
\text { households } \\
\text { (1) } \\
\text { OLS }\end{array}$ & $\begin{array}{c}\text { Households with } \\
\text { younger children } \\
\text { (2) } \\
\text { OLS }\end{array}$ & $\begin{array}{c}\text { All eligible } \\
\text { households } \\
\text { (3) } \\
\text { OLS }\end{array}$ & $\begin{array}{c}\text { Panel } \\
\text { households } \\
\text { (4) } \\
\text { OLS }\end{array}$ & $\begin{array}{c}\text { Panel } \\
\text { households (IPW) } \\
\text { (5) } \\
\text { OLS }\end{array}$ \\
\hline Mother municipality & $\begin{array}{c}0.870 \\
(1.355)\end{array}$ & $\begin{array}{c}0.996 \\
(1.406)\end{array}$ & $\begin{array}{l}3.733^{* *} \\
(1.569)\end{array}$ & $\begin{array}{c}3.551^{* *} \\
(1.689)\end{array}$ & $\begin{array}{l}3.760 * * \\
(1.727)\end{array}$ \\
\hline Controls & Yes & Yes & Yes & Yes & Yes \\
\hline Observations & 1043 & 694 & 825 & 656 & 656 \\
\hline
\end{tabular}

Note. Standard errors clustered at municipality level in parenthesis. $* * *$ denotes significance at $1 \%$, $* *$ at $5 \%$, and $*$ at $10 \%$. Food budget share is defined as the ratio between food expenditure and total household expenditure on non-durables. Budget shares are multiplied by 100. Mother municipality is an indicator variable equal to 1 if the transfer is made to mothers and zero otherwise. Columns 1-2 are estimated using baseline data, while columns 3-5 are estimated using follow-up data. Columns 4-5 restrict the sample to only households interviewed at baseline and follow-up. Column 5 uses inverse probability weighting (IPW) to correct for attrition (Wooldridge, 2010). Controls include age and education of partners, ethnicity dummies, household size and composition, regional dummies, indicator variables for rural area and for capital city.

\section{B.3 Effect on the decision to purchase}

In this section, we look specifically at the share of non-zero consumption for each item. For each item, we build dummy variables equal to 1 if the item was consumed and zero otherwise and we compute ITT estimates for the effect of residing in a Mother municipality.

We start by focusing on budget shares. Table B5 presents descriptive statistics about non-zero expenditures and mean difference between Mother and HH municipalities. Columns 1-4 refer to baseline, while columns 5-8 refer to the follow-up. Column 8 shows that for most items there is no difference at follow-up. Especially for food, we can observe that $100 \%$ of household consumed it in the sample, suggesting that the effect on food shares is not linked to the frequency of purchase.

Table B5: Non zero expenditures, by treatment status

\begin{tabular}{|c|c|c|c|c|c|c|}
\hline & \multicolumn{3}{|c|}{ BASELINE } & \multicolumn{3}{|c|}{ FOLLOW-UP } \\
\hline & (1) & (2) & (3) & (4) & $(5)$ & (6) \\
\hline & $\mathrm{HH}$ & Mother & Difference & $\mathrm{HH}$ & Mother & Difference \\
\hline \multirow[t]{2}{*}{ Food } & 1.00 & 1.00 & 0.00 & 1.00 & 1.00 & -0.00 \\
\hline & {$[0.00]$} & {$[0.00]$} & $(0.00)$ & {$[0.00]$} & [0.04] & $(0.00)$ \\
\hline \multirow[t]{2}{*}{ Tobacco and Alcohol } & 0.33 & 0.33 & -0.01 & 0.45 & 0.37 & -0.05 \\
\hline & {$[0.47]$} & {$[0.47]$} & $(0.04)$ & {$[0.51]$} & [0.49] & $(0.06)$ \\
\hline \multirow[t]{2}{*}{ Clothing } & 0.80 & 0.82 & 0.04 & 0.84 & 0.76 & -0.06 \\
\hline & {$[0.40]$} & {$[0.38]$} & $(0.04)$ & {$[0.38]$} & {$[0.44]$} & $(0.04)$ \\
\hline \multirow[t]{2}{*}{ Education } & 0.81 & 0.88 & 0.05 & 0.91 & 0.87 & -0.04 \\
\hline & [0.39] & {$[0.32]$} & $(0.04)$ & {$[0.31]$} & {$[0.35]$} & $(0.03)$ \\
\hline \multirow{2}{*}{ Health } & 0.97 & 1.00 & $0.02 *$ & 0.98 & 0.98 & -0.01 \\
\hline & {$[0.16]$} & {$[0.06]$} & $(0.01)$ & [0.15] & {$[0.16]$} & $(0.01)$ \\
\hline \multirow[t]{2}{*}{ Utilities and other expenses } & 1.00 & 1.00 & -0.00 & 1.00 & 0.99 & -0.01 \\
\hline & {$[0.00]$} & {$[0.06]$} & $(0.00)$ & {$[0.00]$} & {$[0.11]$} & $(0.00)$ \\
\hline Observations & 515 & 528 & 1043 & 410 & 415 & 825 \\
\hline Demographic controls & - & - & Yes & - & - & Yes \\
\hline
\end{tabular}

Note. Standard deviations in brackets, standard errors clustered at municipality level in parenthesis. $* * *$ denotes significance at $1 \%$, $* *$ at $5 \%$, and $*$ at $10 \%$. Non-zero expenditures are defined as a dummy variable equal to one if the household consumed the item and zero otherwise. In columns 3 and 6 differences are estimated from running the corresponding least squares regression on the Mother municipality dummy, equal to 1 if the transfer is made to mothers and zero otherwise. Demographic controls include age and education of partners, ethnicity dummies, household size and composition, regional dummies, indicator variables for rural area and for capital city. 
We can proceed by looking at food categories within the food basket. Table B6 presents the same analysis for each food categories within the food basket. We cannot identify an effect on the propensity to purchase a specific item, apart from an increase in the probability to purchase of fruit and vegetables, significant only at $10 \%$.

Table B6: Non zero expenditures for food items, by treatment status

\begin{tabular}{l|ccc|ccc}
\hline \hline & & BASELINE & & \multicolumn{3}{c}{ FOLLOW-UP } \\
& $(1)$ & $(2)$ & $(3)$ & $(4)$ & $(5)$ & $(6)$ \\
& HH & Mother & Difference & HH & Mother & Difference \\
\hline Starches & 1.00 & 1.00 & 0.00 & 0.99 & 1.00 & 0.01 \\
& {$[0.00]$} & {$[0.00]$} & $(0.00)$ & {$[0.10]$} & {$[0.05]$} & $(0.00)$ \\
Meat, fish and dairy & 0.99 & 0.99 & -0.01 & 0.98 & 0.99 & 0.00 \\
& {$[0.09]$} & {$[0.11]$} & $(0.01)$ & {$[0.12]$} & {$[0.11]$} & $(0.01)$ \\
Fruit and vegetables & 0.86 & 0.86 & 0.02 & 0.89 & 0.94 & $0.05^{*}$ \\
& {$[0.35]$} & {$[0.34]$} & $(0.03)$ & {$[0.31]$} & {$[0.24]$} & $(0.02)$ \\
Salt and sugars & 0.94 & 0.96 & 0.02 & 0.97 & 0.97 & -0.00 \\
& {$[0.23]$} & {$[0.20]$} & $(0.02)$ & {$[0.18]$} & {$[0.18]$} & $(0.02)$ \\
Other food & 0.06 & 0.05 & -0.00 & 0.09 & 0.09 & -0.01 \\
& {$[0.23]$} & {$[0.22]$} & $(0.02)$ & {$[0.30]$} & {$[0.30]$} & $(0.03)$ \\
\hline Observations & 519 & 533 & 1052 & 412 & 416 & 828 \\
Demographic controls & - & - & Yes & - & - & Yes \\
\hline \hline
\end{tabular}

Note. Standard deviations in brackets, standard errors clustered at municipality level in parenthesis. $* * *$ denotes significance at $1 \%$, $* *$ at $5 \%$, and $*$ at $10 \%$. Non-zero expenditures are defined as a dummy variable equal to one if the household consumed the item and zero otherwise. In columns 3 and 6 differences are estimated from running the corresponding least squares regression on the Mother municipality dummy, equal to 1 if the transfer is made to mothers and zero otherwise. Demographic controls include age and education of partners, ethnicity dummies, household size and composition, regional dummies, indicator variables for rural area and for capital city.

\section{B.4 Prices and food budget shares}

To study how food expenditure is allocated to different food categories, we estimate equation (2) for each food category and we compute the derivative with respect to food (log-)expenditure and with respect to the food price index. Table B7 presents the estimated coefficients and the standard errors for both derivatives. We can observe that, while food expenditure increases, households tend to allocate a lower share to bread and potatoes and a higher share on meat, fruit, cheese, chocolate and sugars. In terms of sensitivity to food prices, we observe that pasta and rice, lipids of vegetable origin and pulses are negatively responding to increases in the food price index, while the share of manufactured vegetables tend to increase.

In order to check whether prices were presenting a balanced distribution across different types of municipalities and to estimate the effect of the payment modalities on food prices, Table B8 presents instead a comparison of prices by group of municipality. We observe no difference in the computed prices in the two groups both at baseline and follow-up. This suggests that the introduction of different payment modalities for the CCT program did not induce any effect on food prices.

While prices are balanced across municipalities, in order to estimate Engel curves we aim at exploiting a geographic variation in prices, but limited variation could limit our analysis. Figure B2 shows the distribution of the Stone Price index across municipalities and across time (for baseline 
Table B7: Food budget shares, total food expenditure and food prices

\begin{tabular}{|c|c|c|c|c|c|}
\hline & \multirow{4}{*}{$\begin{array}{c}\text { (1) } \\
\text { Average share }\end{array}$} & \multicolumn{4}{|c|}{ Derivative with respect to... } \\
\hline & & \multicolumn{2}{|c|}{ Total food expenditure } & \multicolumn{2}{|c|}{ Food price index } \\
\hline & & (2) & (3) & (4) & $(5)$ \\
\hline & & Coefficient & Std.error & Coefficient & Std.error \\
\hline Bread & 17.13 & $-16.67 * * *$ & 4.83 & -37.68 & 30.08 \\
\hline Butter & 0.74 & 0.12 & 0.33 & 2.25 & 2.78 \\
\hline Pasta and rice & 2.55 & 1.00 & 0.65 & $-16.98 * * *$ & 5.07 \\
\hline Cheese & 3.78 & $4.00 * * *$ & 1.46 & 2.12 & 11.05 \\
\hline Chocolate and biscuits & 1.41 & $1.93 * * *$ & 0.62 & 6.36 & 4.73 \\
\hline Coffee and tea & 4.34 & -0.15 & 0.84 & 11.34 & 7.31 \\
\hline Dry fruit & 0.22 & -0.32 & 0.40 & 6.96 & 4.86 \\
\hline Eggs & 3.33 & -0.13 & 1.04 & 4.47 & 8.05 \\
\hline Fish & 0.91 & 0.32 & 0.57 & 9.33 & 6.09 \\
\hline Food and drinks outside & 1.23 & $1.99 *$ & 1.08 & 2.79 & 8.30 \\
\hline Fresh vegetables & 6.43 & 0.78 & 1.85 & 15.89 & 11.40 \\
\hline Fruit & 3.13 & $3.67 * * *$ & 0.70 & 5.21 & 9.19 \\
\hline Lipids of animal origin & 0.12 & -0.12 & 0.17 & 0.47 & 1.30 \\
\hline Lipids of vegetable origin & 7.07 & 0.82 & 1.56 & $-17.32 *$ & 10.21 \\
\hline Manufactured meat & 2.17 & 0.61 & 0.87 & 1.12 & 8.74 \\
\hline Manufactured vegetables & 1.56 & -0.09 & 0.82 & $16.22 *$ & 8.20 \\
\hline Milk and yoghurt & 4.98 & -1.47 & 2.47 & 16.27 & 12.94 \\
\hline Meat & 11.31 & $7.09 * * *$ & 2.00 & -7.44 & 17.76 \\
\hline Other food items & 0.04 & 0.09 & 0.13 & 0.48 & 0.53 \\
\hline Potatoes & 3.18 & $-3.39^{*}$ & 1.76 & -7.62 & 7.67 \\
\hline Pulses & 4.61 & -0.76 & 1.60 & $-20.27 *$ & 11.66 \\
\hline Salt and salties & 1.59 & 0.07 & 0.48 & 1.41 & 4.81 \\
\hline Soft drinks & 3.16 & 1.41 & 0.97 & 16.34 & 9.88 \\
\hline Sugar and honey & 3.02 & 1.62 & 0.98 & -9.56 & 7.76 \\
\hline Wheat & 11.99 & -2.39 & 3.92 & -2.18 & 28.59 \\
\hline
\end{tabular}

Note. Standard deviations in brackets, standard errors in parenthesis. $* * *$ denotes significance at $1 \%$, ** at $5 \%$, and $*$ at $10 \%$. Food budget shares are defined as the ratio between the consumption deriving from a specific source and the total food consumption. Total food expenditure and Food price are both reported in logarithms.

Table B8: Average Stone Price Indexes, by treatment status

\begin{tabular}{|c|c|c|c|c|c|c|}
\hline & \multicolumn{3}{|c|}{ BASELINE } & \multicolumn{3}{|c|}{ FOLLOW-UP } \\
\hline & (1) & $(2)$ & (3) & (4) & $(5)$ & (6) \\
\hline & $\mathrm{HH}$ & Mother & Difference & $\mathrm{HH}$ & Mother & Difference \\
\hline \multirow{2}{*}{ Price index (Food) } & 2.16 & 2.17 & 0.01 & 2.27 & 2.27 & 0.01 \\
\hline & {$[0.06]$} & {$[0.06]$} & $(0.01)$ & {$[0.06]$} & {$[0.05]$} & $(0.01)$ \\
\hline \multirow[t]{2}{*}{ Price index (Starches) } & 1.69 & 1.71 & 0.03 & 1.74 & 1.76 & 0.02 \\
\hline & {$[0.11]$} & {$[0.11]$} & $(0.02)$ & {$[0.10]$} & [0.09] & $(0.02)$ \\
\hline \multirow[t]{2}{*}{ Price index (Fruit and vegetables) } & 1.16 & 1.15 & -0.01 & 1.24 & 1.24 & -0.01 \\
\hline & {$[0.11]$} & [0.11] & $(0.02)$ & {$[0.10]$} & {$[0.10]$} & $(0.02)$ \\
\hline \multirow[t]{2}{*}{ Price index (Meat, fish and dairy) } & 2.82 & 2.82 & -0.00 & 2.98 & 2.98 & 0.00 \\
\hline & {$[0.06]$} & {$[0.05]$} & $(0.01)$ & {$[0.08]$} & {$[0.07]$} & $(0.02)$ \\
\hline \multirow[t]{2}{*}{ Price index (Salt and sugars) } & 2.37 & 2.36 & -0.01 & 2.50 & 2.50 & -0.00 \\
\hline & {$[0.09]$} & {$[0.07]$} & $(0.02)$ & {$[0.07]$} & [0.09] & $(0.02)$ \\
\hline \multirow[t]{2}{*}{ Price index (Other food) } & 2.73 & 2.71 & -0.03 & 2.77 & 2.76 & -0.01 \\
\hline & {$[0.21]$} & {$[0.24]$} & $(0.05)$ & {$[0.20]$} & {$[0.25]$} & $(0.05)$ \\
\hline Observations & 42 & 41 & 83 & 42 & 41 & 83 \\
\hline Demographic controls & - & - & No & - & - & No \\
\hline
\end{tabular}

Note. Standard deviations in brackets, standard errors clustered at municipality level in parenthesis. *** denotes significance at $1 \%$, $* *$ at $5 \%$, and $*$ at $10 \%$. Prices indexes are averaged at municipality level. Detailed information about the construction of the indexes is reported in Section 3.2.1. In columns 3 and 6 differences are estimated from running the corresponding least squares regression on the Mother municipality dummy, equal to 1 if the transfer is made to mothers and zero otherwise. 
and for the follow-up). While we observe little variation across time, we can observe that variation is substantial across municipalities, with the western part of Macedonia being characterized by higher prices.

Figure B2: Geographical variation in Stone Price Index for Food at Baseline and Follow-up
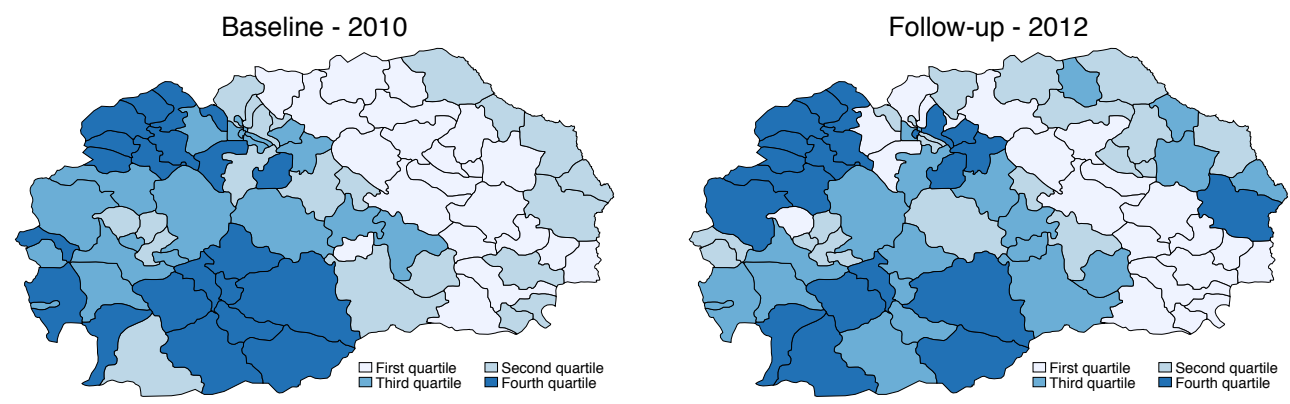

Note. The left panel shows the geographical variation of a Stone Price Index for food computed at Baseline, while the right panel presents it for the Follow-up. See Section 3.2.2 for a discussion about the computation of the Index.

\section{B.5 Engel curve estimates for other goods}

In the main text, we focused only on the estimation of the Engel curves for food and food items. In this section, we present share equation estimates for expenditure shares on tobacco and alcohol, clothing, education, health and utilities and other expenses.

Table B9 presents estimates for Engel curves using equation 2. In column 1 we estimate the impact of being assigned to a municipality where the mother is paid on the intercept of the Engel curve, and in column 2 we also interact this variable with household expenditure, thereby allowing it to also affect the slope of the Engel curve. In columns 3-4 of this table we investigate the impacts on the Engel curve of the actual receipt of the transfer by a woman, i.e., we use an indicator for whether the woman received or not a transfer, instrumented with the type of municipality she resides in.

\section{B.6 Time use}

We collected information on the amount of time spent by both parents the day before the interview on different activities. We report the total time (expressed as share of the day) spent by both mothers and fathers on the following activities: sleeping, doing house chores, working, taking care of elderly, shopping, leisure with children, leisure without children, helping children to study and doing other activities (with and without children). Table B10 presents differences in the allocation of day shares between treatment groups at baseline and follow-up for mothers and fathers. We can observe that no difference is significant at both baseline and follow-up, providing evidence that the targeting of payments to mothers or household heads had no impact on time use. 
Table B9: Demand system for other goods

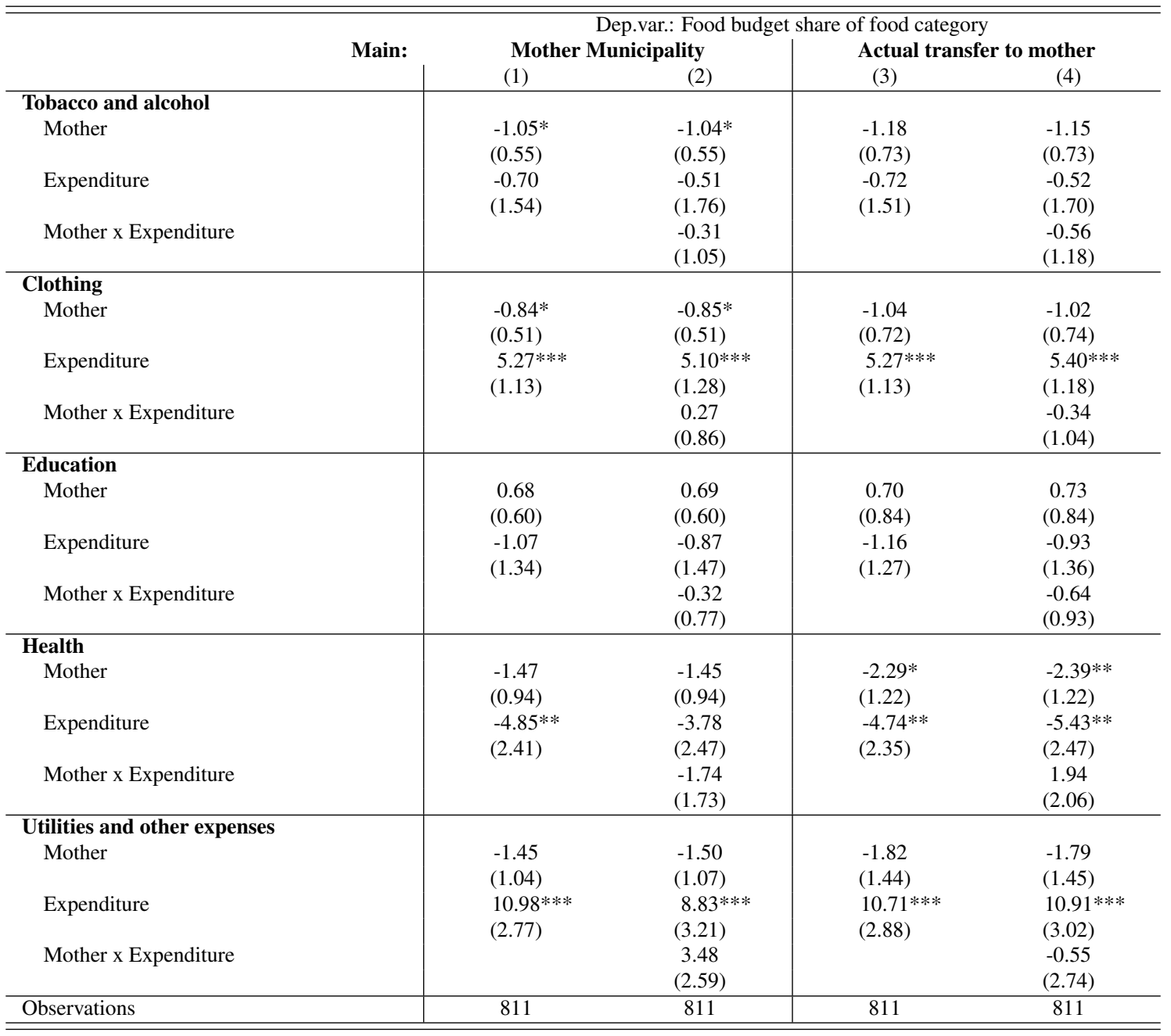

Note. Bootstrap standard errors clustered by municipality (2000 replications) are presented in parentheses. $* * *$ denotes significance at $1 \%$, ** at $5 \%$, and $*$ at $10 \%$. Dependent variable is the the budget share on the good, defined as the ratio between the expenditure on the good and the total household expenditure. "Expenditure" is total household expenditure on non-durable demeaned. In columns $1-2$, the main variable is the "Mother municipality" dummy variable, equal to 1 if the household resides in a municipality where the CCT payment is transferred to women and 0 otherwise. In columns 3-4, the main effect is a dummy variable equal to 1 if a woman received at least one payment during the first two years of the program and is instrumented using the "Mother municipality" dummy as instrument. Controls include age and education of partners, ethnicity dummies, household size and composition, regional dummies, indicator variables for rural area and for capital city, food price control and the number of children enrolled in school. Endogenous variables are instrumented using a control function approach (see section 4.2). The endogeneity test is performed as a joint Wald test for the equality to zero of all coefficients in the polynomial of residuals. 
Table B10: Share of the day spent on different activities by treatment status

\begin{tabular}{|c|c|c|c|c|c|c|}
\hline & \multicolumn{3}{|c|}{ BASELINE } & \multicolumn{3}{|c|}{ FOLLOW-UP } \\
\hline & (1) & (2) & (3) & (4) & (5) & (6) \\
\hline & $\mathrm{HH}$ & Mother & Difference & $\mathrm{HH}$ & Mother & Difference \\
\hline \multicolumn{7}{|l|}{ FATHERS } \\
\hline \multirow[t]{2}{*}{ Sleeping } & 0.379 & 0.384 & 0.004 & 0.384 & 0.383 & -0.001 \\
\hline & {$[0.062]$} & {$[0.065]$} & $(0.009)$ & {$[0.058]$} & {$[0.065]$} & $(0.009)$ \\
\hline \multirow[t]{2}{*}{ House chores and working } & 0.217 & 0.223 & 0.005 & 0.230 & 0.232 & 0.002 \\
\hline & [0.159] & {$[0.153]$} & $(0.024)$ & {$[0.186]$} & {$[0.203]$} & $(0.030)$ \\
\hline \multirow[t]{2}{*}{ Time with children } & 0.136 & 0.135 & -0.002 & 0.128 & 0.144 & 0.016 \\
\hline & [0.109] & [0.114] & $(0.015)$ & [0.139] & {$[0.143]$} & $(0.021)$ \\
\hline \multirow[t]{2}{*}{ Shopping and leisure } & 0.146 & 0.141 & -0.005 & 0.142 & 0.128 & -0.013 \\
\hline & {$[0.127]$} & {$[0.129]$} & $(0.018)$ & {$[0.125]$} & {$[0.122]$} & $(0.017)$ \\
\hline \multirow[t]{2}{*}{ Other activities } & 0.121 & 0.118 & -0.003 & 0.116 & 0.112 & -0.004 \\
\hline & {$[0.127]$} & {$[0.128]$} & $(0.018)$ & {$[0.161]$} & {$[0.158]$} & $(0.026)$ \\
\hline Observations & 428 & 448 & 876 & 399 & 404 & 803 \\
\hline \multicolumn{7}{|l|}{ MOTHERS } \\
\hline \multirow[t]{2}{*}{ Sleeping } & 0.365 & 0.370 & 0.005 & 0.381 & 0.382 & 0.001 \\
\hline & {$[0.058]$} & {$[0.062]$} & $(0.008)$ & [0.059] & {$[0.060]$} & $(0.008)$ \\
\hline \multirow[t]{2}{*}{ House chores and working } & 0.217 & 0.223 & 0.005 & 0.230 & 0.232 & 0.002 \\
\hline & [0.159] & {$[0.153]$} & $(0.024)$ & {$[0.186]$} & {$[0.203]$} & $(0.030)$ \\
\hline \multirow[t]{2}{*}{ Time with children } & 0.158 & 0.156 & -0.002 & 0.134 & 0.141 & 0.008 \\
\hline & {$[0.115]$} & [0.111] & $(0.013)$ & [0.111] & {$[0.121]$} & $(0.016)$ \\
\hline \multirow[t]{2}{*}{ Shopping and leisure } & 0.079 & 0.079 & -0.000 & 0.086 & 0.087 & 0.002 \\
\hline & {$[0.096]$} & {$[0.085]$} & $(0.009)$ & {$[0.089]$} & {$[0.094]$} & $(0.011)$ \\
\hline \multirow[t]{2}{*}{ Other activities } & 0.075 & 0.075 & 0.001 & 0.057 & 0.061 & 0.004 \\
\hline & [0.100] & [0.099] & $(0.013)$ & [0.084] & [0.093] & $(0.011)$ \\
\hline Observations & 454 & 498 & 952 & 397 & 413 & 810 \\
\hline
\end{tabular}

Note. Standard deviations in brackets, standard errors in parenthesis. $* * *$ denotes significance at $1 \%$, $* *$ at $5 \%$, and $*$ at $10 \%$. Dependent variable is the share of the day spent by fathers (upper panel) and mothers (lower panel) on different activities. The standard errors on the differences are estimated from running the corresponding least squares regression on treatment status allowing for the errors to be clustered at municipality level. Treatment status is equal to 1 if the transfer is made to mothers and zero otherwise. 